\title{
Spatial and Temporal Patterns of Small-Scale Mixing in Drake Passage
}

\author{
ANDREW F. THOMPSON \\ Scripps Institution of Oceanography, University of California, San Diego, La Jolla, California \\ SARAh T. GiLle \\ Scripps Institution of Oceanography, and Department of Mechanical and Aerospace Engineering, University of California, San \\ Diego, La Jolla, California \\ J. A. MacKinnon And Janet SPRintall \\ Scripps Institution of Oceanography, University of California, San Diego, La Jolla, California
}

(Manuscript received 9 November 2005, in final form 26 June 2006)

\begin{abstract}
Temperature and salinity profiles obtained with expendable CTD probes throughout Drake Passage between February 2002 and July 2005 are analyzed to estimate turbulent diapycnal eddy diffusivities to a depth of $1000 \mathrm{~m}$. Diffusivity values are inferred from density/temperature inversions and internal wave vertical strain. Both methods reveal the same pattern of spatial variability across Drake Passage; diffusivity estimates from inversions exceed those from vertical strain by a factor of 3 over most of Drake Passage. The Polar Front (PF) separates two dynamically different regions. Strong thermohaline intrusions characterize profiles obtained north of the PF. South of the PF, stratification is determined largely by salinity, and temperature is typically unstably stratified between 100 - and $600-\mathrm{m}$ depth. In the upper $400 \mathrm{~m}$, turbulent diapycnal diffusivities are $O\left(10^{-3} \mathrm{~m}^{2} \mathrm{~s}^{-1}\right)$ north of the PF but decrease to $O\left(10^{-4} \mathrm{~m}^{2} \mathrm{~s}^{-1}\right)$ or smaller south of the PF. Below $400 \mathrm{~m}$ diffusivities typically exceed $10^{-4} \mathrm{~m}^{2} \mathrm{~s}^{-1}$. Diffusivities decay weakly with depth north of the PF, whereas diffusivities increase with depth and peak near the local temperature maximum south of the PF. The meridional pattern in near-surface mixing corresponds to local maxima and minima of both wind stress and wind stress variance. Near-surface diffusivities are also found to be larger during winter months north of the PF. Wind-driven near-inertial waves, strong mesoscale eddy activity, and doublediffusive convection are suggested as possible factors contributing to observed mixing patterns.
\end{abstract}

\section{Introduction}

Observations in the Southern Ocean suggest that mixing is intense and widespread, even well above rough topography. Naveira Garabato et al. (2004) analyze velocity fluctuations caused by the internal wave field in Drake Passage and the Scotia Sea to show that turbulent diapycnal eddy diffusivities $\kappa_{\rho}$ can exceed

Corresponding author address: Andrew F. Thompson, School of Environmental Sciences, University of East Anglia, Norwich NR4 7TJ, United Kingdom.

E-mail: andrew.f.thompson@uea.ac.uk background values by up to three orders of magnitude. They further find that values of $\kappa_{\rho}$ greater than $10^{-3}$ $\mathrm{m}^{2} \mathrm{~s}^{-1}$ extend more than $2000 \mathrm{~m}$ above the bottom. From analysis of strain variance in the World Ocean Circulation Experiment (WOCE) hydrographic profiles of the Southern Hemisphere, Sloyan (2005) shows that enhanced mixing above topography occurs throughout the Southern Ocean. Also, unlike midlatitude ocean basins where diffusivities return to background levels within $1000 \mathrm{~m}$ of the bottom, elevated diffusivities are found up to depths of at least $1500 \mathrm{~m}$ (Sloyan 2005). The detection of elevated mixing rates in the Southern Ocean suggests that diapycnal mixing significantly influences local dynamics.

However, the pathways through which mixing influ-

DOI: $10.1175 / J P O 3021.1$

(C) 2007 American Meteorological Society 
ences Southern Ocean dynamics are not well understood, mainly because the Southern Ocean has many features that differentiate it from other ocean basins. The Southern Ocean is subject to wind forcing and mesoscale eddy activity that are well above mid- and lowlatitude levels (Rintoul et al. 2001; Sprintall 2003). Zonal velocities are also significantly larger in the Southern Ocean because of the strong Antarctic Circumpolar Current (ACC). Furthermore, within the ACC, isopycnals slope upward toward the surface and can outcrop, allowing deep and intermediate waters to be affected by wind and buoyancy forcing. Speer et al. (2000) describe how surface fluxes convert upwelled water into Intermediate Water and Subantarctic Mode Water, which are then advected away from the outcropping site. Thus the Southern Ocean is subject to a number of unique forcings, and it is unclear whether mixing descriptions (e.g., subgrid-scale parameterizations in large-scale climate models) based upon mid- and lowlatitude physics are appropriate at higher southern latitudes.

This uncertainty about the relative importance of mixing in Southern Ocean dynamics has led to a disparity in how diapycnal mixing is incorporated in models of the Southern Ocean's meridional circulation. Historically, it is thought that a balance between winddriven Ekman flow and mesoscale eddies determines the meridional circulation (Johnson and Bryden 1989; Speer et al. 2000). In the studies of Karsten et al. (2002) and Bryden and Cunningham (2003), diapycnal mixing has little effect on Southern Ocean dynamics. Instead, subsurface mixing occurs primarily along isopycnals and all diapycnal exchanges are limited to surface processes. However, Cessi and Fantini (2004) suggest that diapycnal mixing plays a prominent role in determining the deep stratification of the Southern Ocean. Cessi and Fantini (2004) also find that the depth of the thermocline can depend on the magnitude of $\kappa_{\rho}$. A more complete understanding of diapycnal mixing processes in this region is necessary to assess the validity of the various proposed circulation models.

Additionally, a better understanding of diapycnal mixing processes in the Southern Ocean may offer a solution to the long-standing global "missing mixing" problem. Munk's (1966) estimate of a uniform diapycnal eddy diffusivity, $\kappa_{\rho}=10^{-4} \mathrm{~m}^{2} \mathrm{~s}^{-1}$, assumes that nearly all North Atlantic Deep Water (NADW) upwells at low latitudes. The discrepancy between this predicted value and observed open ocean values, which are an order of magnitude smaller (Gregg 1987; Toole et al. 1994; Kunze and Sanford 1996), is partially explained by the patchiness of low-latitude turbulence; that is, turbulence is elevated over rough topography
(Polzin et al. 1997). As an alternative solution, Toggweiler and Samuels (1995) propose that conversion of NADW into new water masses through upwelling and mixing in the Southern Ocean may effectively short circuit the low-latitude diapycnal mixing described by Munk (1966). Conversion of NADW depends on both the magnitude and distribution of diapycnal mixing and the rate at which upwelled water is exported to other ocean basins via the meridional circulation. Significant NADW upwelling in the Southern Ocean would reduce the low-latitude value of $\kappa_{\rho}$ needed for mass conservation.

Unfortunately, mixing rates in the Southern Ocean remain poorly constrained, primarily because few direct observations exist in the region. The remoteness and harsh conditions of the Southern Ocean have so far prevented extensive microstructure measurements that can explicitly resolve small-scale diapycnal mixing. Although this leaves some uncertainty in the quantitative description of mixing rates, the results of previous Southern Ocean-based studies (Polzin and Firing 1997; Naveira Garabato et al. 2004; Sloyan 2005) clearly show that mixing processes in this region are characterized by strong spatial intermittency.

Kunze (2003), Naveira Garabato et al. (2004), and Sloyan (2005) all focus on abyssal mixing processes and offer little information about the temporal variability of the mixing events. In fact, few studies have addressed the temporal variability of mixing events in the open ocean. Gregg (1977) and Finnegan et al. (2002) present open-ocean mixing measurements repeated at the same location during different seasons. Gregg (1977) provides some evidence of seasonal dependence, while numerical studies (Nagasawa et al. 2000) have confirmed that the intensity of internal waves can vary in response to seasonal changes in the wind stress. Finnegan et al. (2002), who focus on topographic effects, do not comment on any temporal variability.

With the importance of both spatial and temporal variability in mind, we analyze a unique dataset collected in Drake Passage over the past five years as part of the Scripps Institution of Oceanography's (SIO) high-resolution XBT/expendable CTD (XCTD) network. This study departs from previous studies in Drake Passage by concentrating on mixing events in the upper $1000 \mathrm{~m}$ of the water column. Small-scale mixing rates are inferred from finescale observations using the Thorpe scale method (Dillon 1982), which requires detecting turbulent overturns in an otherwise stable density profile. We also analyze vertical strain spectra as an independent measure of turbulent diffusivities. Our results focus primarily upon the observed spatial mixing 
patterns with a view toward understanding what processes dominate upper-ocean mixing in the Southern Ocean.

To our knowledge, this is the first study that determines small-scale mixing rates from XCTD data. While XCTDs have slightly higher noise than traditional CTDs, this is compensated by the fact that XCTDs do not suffer the same error associated with ship roll. We show that, with sufficient coverage, XCTDs (and possibly XBTs in regions where density is largely independent of salinity) provide a relatively inexpensive method for estimating the magnitude and spatial variability of mixing rates. However, XCTDs do not offer the accuracy or physical insight afforded by microstructure measurements.

We discuss both the Thorpe scale and the vertical strain spectral methods in section 2. A description of the dataset and our processing techniques appears in section 3, which also includes a comparison with other Thorpe scale studies. We discuss our results in section 4 with emphasis on spatial and seasonal variations in mixing intensity. Thorpe scale estimates are also compared with estimates obtained from the strain spectral analysis. We suggest possible mechanisms for the observed spatial and temporal patterns in section 5, and our conclusions appear in section 6 .

\section{Background}

\section{a. Thorpe scales}

Because of the expensive nature of collecting ocean data at microscale resolution, many theories have been proposed that allow small-scale mixing rates to be estimated from coarser-resolution data. A basic goal is to determine the kinetic energy dissipation rate $\varepsilon$, which is related to the stratification and a turbulent mixing length, the Ozmidov scale $L_{O}$ (Ozmidov 1965), by

$$
\varepsilon=L_{O}^{2} N^{3},
$$

where $N^{2}=-g \rho_{0}^{-1}(d \rho / d z)$ is the squared buoyancy frequency. Ferron et al. (1998) offer the physical explanation that $L_{O}$ corresponds to the vertical distance $l$ that a particle of fluid moves if all of its kinetic energy is converted to potential energy (assuming that $\varepsilon \sim w^{3} / l$, where $w$ is a vertical velocity scale). Therefore $L_{O}$ is a measure of the maximum size of an overturn in a stratified fluid. It is difficult to obtain an estimate for $L_{O}$ independently since $\varepsilon$ can only be resolved with centimeter-scale microstructure measurements.

The Thorpe scale $L_{T}$ (Thorpe 1977; Dillon 1982) provides a length associated with the size of density overturns in an otherwise stably stratified fluid. The method involves reordering a potential density profile that may contain inversions into a stable monotonic profile. Anywhere in the initial profile where a gravitational instability exists, the displacement from the original position to the reordered position, known as the Thorpe displacement $d^{\prime}$, is nonzero. The root-mean-square of the Thorpe displacements associated with a single overturn region gives the Thorpe scale $L_{T}$ for that turbulent event, or

$$
L_{T} \equiv \sqrt{\left\langle d^{\prime 2}\right\rangle}
$$

where angle brackets indicate an average over a single overturn. Although overturns are not one-dimensional, the Thorpe scale gives a good estimate of an overturn size as long as the mean horizontal gradient is much smaller than the vertical gradient, which is satisfied in the Southern Ocean.

Since $L_{O}$ and $L_{T}$ are two different estimates of overturning lengths, it is reasonable to expect that a linear relationship exists between the two, although spatial and temporal variability in the turbulent field means that any relation is only valid in a statistical sense. Dillon (1982) studies the relationship between $L_{O}$ and $L_{T}$ and finds that $L_{O}=(0.8 \pm 0.4) L_{T}$. A number of other studies followed, including Crawford (1986), who proposes a smaller coefficient $L_{O}=(0.66 \pm 0.27) L_{T}$ for an oceanic thermocline, and Ferron et al. (1998), who propose a larger coefficient $L_{O}=(0.95 \pm 0.6) L_{T}$ for an abyssal region. The errors of both of these studies overlap Dillon's (1982) original results, which we will apply in our present analysis. This then implies that the turbulent dissipation of an individual overturn can be calculated directly from the buoyancy frequency and the Thorpe scale. Using (1) gives

$$
\varepsilon_{i}=0.64 L_{T i}^{2}\langle N\rangle_{i}^{3},
$$

where subscript $i$ refers to the $i$ th overturn.

Turbulent dissipation is often converted to a diapycnal eddy diffusivity $\kappa_{\rho}$ using the model given in Osborn (1980), where

$$
\kappa_{\rho}=\Gamma \varepsilon N^{-2} .
$$

The mixing efficiency $\Gamma$ has been shown to vary depending on the origin of the turbulence (Caldwell and Moum 1995), although most studies assume that $\Gamma$ is a constant equal to 0.2 . We will follow this convention as well.

There is an important distinction between the two values of $N$ used in the calculation of $\varepsilon$ and $\kappa_{\rho}$. In determining the dissipation of a single overturn, the buoyancy frequency in (3) should be the mean value of $N$ in the reordered region of the overturn, or $\langle N\rangle_{i}$, since overturns occur preferentially in regions of low strati- 
fication (Alford and Pinkel 2000). The calculation of $\kappa_{\rho}$ in (4) requires that the background buoyancy frequency $N$ be applied since (4) arises from a representation of $\kappa_{\rho}$ as a turbulent diffusion acting on the background density gradient (see discussion in Ferron et al. 1998).

From (3) and (4) we can see that, outside of overturning regions, both $\varepsilon$ and $\kappa_{\rho}$ are zero. Calculation of a depth-averaged quantity includes both overturning and quiet regions. An example is given by

$$
\bar{\varepsilon}=\frac{\sum_{i} \varepsilon_{i} L_{z i}}{H},
$$

where $L_{z i}$ is the size of the $i$ th overturn and $H$ is the depth over which we choose to average. It is important to note that $\bar{\varepsilon}$ can be smaller than the minimum resolvable turbulent dissipation of an individual overturn. To ease notation we will not use overbars and, unless otherwise stated, all symbols refer to depth-averaged quantities for the remainder of the paper.

There remains some uncertainty about the validity of the relationships $L_{O}=0.8 L_{T}$ and $\Gamma=0.2$. Furthermore, the theory surrounding Thorpe scales assumes that the system is in steady state, which is a difficult condition to verify in a region as energetic as the ACC. Therefore we view with some caution the magnitude of the results presented here and focus primarily on the spatial and temporal patterns that appear to be a robust feature of mixing in Drake Passage.

\section{b. Strain spectral analysis}

An independent method of inferring dissipation rates comes from evidence that ocean mixing is related to the energy density of the internal gravity wave field. Nonlinear wave-wave interactions transfer energy and momentum to increasingly smaller-scale waves, which are more likely to break down into turbulence. McComas and Müller (1981) and Henyey et al. (1986) suggest formulas to estimate turbulent dissipation rates by comparing the shape of energy spectra, which are influenced by wave-wave interactions, to the energy spectrum of a canonical internal wave field proposed by Garrett and Munk (1975, hereinafter GM). Gregg (1989) verifies that a correlation exists between the internal wave shear and mixing rates in the open ocean at vertical scales greater than $10 \mathrm{~m}$. Wijesekera et al. (1993) test the various internal-wave-dissipation models and find that, under certain conditions, scalings comparing the strain rates of the internal wave field to the GM spectrum provide better agreement with observational data than the internal wave shear. Wijesekera et al. (1993) also show that reasonable dissipation estimates are obtained even when the wave field varies significantly from the GM form, which is likely the case in Drake Passage.

Vertical strain can be obtained from vertical derivatives of properties such as potential density and temperature (a discussion of our methods appears in section 4d), and Fourier transforming gives the spectral representation $\phi_{\lambda}$. Following Kunze (2003), strain variance levels $\left\langle\xi_{z}^{2}\right\rangle$ are determined by integrating $\phi_{\lambda}$ from a minimum vertical wavenumber $k_{\min }$ out to a maximum wavenumber $k_{\max }$ such that

$$
\left\langle\xi_{z}^{2}\right\rangle=\int_{k_{\min }}^{k_{\max }} \phi_{\lambda} d k=0.2 .
$$

The constant 0.2 in (6) is somewhat arbitrary. We find that varying this constant has a small effect on mixing amplitudes and does not affect the spatial pattern that we describe in section 4d. The GM strain variance level is computed over the same wavenumber band so that

$$
\left\langle\xi_{z}^{2}\right\rangle_{\mathrm{GM}}=\frac{\pi E_{0} b j_{*}}{2} \int_{k_{\min }}^{k_{\max }} \frac{k^{2}}{\left(k+k_{*}\right)^{2}} d k,
$$

where $E_{0}=6.3 \times 10^{-5}$ is the dimensionless energy level, $b=1300 \mathrm{~m}$ is the scale depth of the thermocline, $j_{*}=3$ is the reference mode number, and $2 \pi k_{*}=$ $0.0073\left(N / N_{0}\right)$ is the reference wavenumber with $N_{0}=$ $0.00524 \mathrm{~s}^{-1}$. These parameters are given in Gregg and Kunze (1991). Note that the GM strain spectrum given in (7) is flat for $k \gg k_{*}$. In oceanic data a $k^{-1}$ rolloff is observed at high wavenumbers, which has led to a modification of the GM spectrum by including a factor of $k^{-1}$ in the empirical formula beyond $k=0.1 \mathrm{cpm}$ (Winkel 1998). In our study, the integrations in (6) and (7) occur over the flat part of the GM spectrum.

Once the strain variance levels have been determined, we follow the results of Gregg et al. (2003) and calculate the turbulent diffusivity from the formula

$$
\kappa_{\rho}^{\phi}=\kappa_{0} \frac{\left\langle\xi_{z}^{2}\right\rangle^{2}}{\left\langle\xi_{z}^{2}\right\rangle_{\mathrm{GM}}^{2}} \mathcal{H}\left(R_{\omega}\right) g(f, N),
$$

where $\kappa_{0}=0.05 \times 10^{-4} \mathrm{~m}^{2} \mathrm{~s}^{-1}$. The two functions $\mathcal{H}$ and $\mathcal{g}$ are empirical results that account for changes in the frequency content of the GM wave field and changes in latitude, respectively. Henyey (1991) shows that frequency content is related to the shear/strain ratio $R_{\omega}=\left\langle V_{z}^{2}\right\rangle /\left(N^{2}\left\langle\xi_{z}^{2}\right\rangle\right)$, where $V_{z}$ is the vertical derivative of horizontal velocity. We do not have velocity data to accompany our profiles; therefore we rely on shear/ strain ratio estimates from previous studies. Naveira Garabato et al. (2004) report a consistent mean value of $R_{\omega}$ between 8 and 12, independent of location, and E. 
Kunze (2005, personal communication) also finds values of $R_{\omega}$ between 10 and 20 at high latitudes. Taking $R_{\omega}=10$ with

$$
\mathcal{H}\left(R_{\omega}\right)=\frac{3 R_{\omega}\left(R_{\omega}+1\right)}{4\left(R_{\omega_{\mathrm{GM}}}^{2}\right)} \sqrt{\frac{2}{R_{\omega}-1}}
$$

and $R_{\omega_{\mathrm{GM}}}=3$, we find that the turbulent diffusivity is enhanced by nearly a factor of 5 above regions with typical GM wave fields. Over the range $8<R_{\omega}<20, \mathcal{H}$ varies by a factor of 3.5. The formula given in (9) is equivalent to Eq. (4) of Gregg et al. (2003) multiplied by $\left(R_{\omega} / R_{\omega_{\mathrm{GM}}}\right)^{2}$ to convert from shear variance ratios to strain variance ratios.

The latitude dependence also tends to enhance mixing at high latitudes, although we find that the effect is less influential than the shear ratio dependence. The function $\mathcal{I}$ is given by

$$
g(f, N)=\frac{f \cosh ^{-1}(N / f)}{f_{30} \cosh ^{-1}\left(N_{0} / f_{30}\right)},
$$

where $N_{0}$ is defined above and $f_{30}=f\left(30^{\circ}\right)=7.29 \times$ $10^{-5} \mathrm{~s}^{-1}$. Applying characteristic Drake Passage values to (10), $N=2.5 \times 10^{-3} \mathrm{~s}^{-1}$ and $f_{58}=1.2 \times 10^{-4} \mathrm{~s}^{-1}$, we find that the amplification is small with $g \approx 1.25$. The factor $\mathcal{g}$ has a stronger effect at low latitudes and has been used by Gregg et al. (2003) to explain the observation of reduced mixing near the equator.

\section{Measurements}

\section{a. Measurement location}

Since 1996 the high-resolution XBT/XCTD Network maintained by SIO has collected temperature and salinity data in Drake Passage along WOCE-designated transect AX22 between Tierra del Fuego and the Antarctic Penninsula (Fig. 1). Starting in February 2002, the Sippican Digital XCTD was introduced, which has an improved vertical resolution of approximately 0.13 $\mathrm{m}$. During each subsequent cruise, six XCTDs were released at the following latitudes: $56.0^{\circ}, 57.0^{\circ}, 57.5^{\circ}$, $58.0^{\circ}, 59.0^{\circ}$ and $60.5^{\circ} \mathrm{S} .{ }^{1}$ Since 2002,22 transects have been completed with XCTD data. After discarding erroneous profiles, we analyze no less than 19 individual profiles at each of the six latitude locations. These profiles are roughly evenly divided between summer and winter months. Figure 1 indicates the position of each

\footnotetext{
${ }^{1}$ The XBTs, which only measure temperature, have a finer horizontal resolution of 15-20 km. We only analyze XCTDs since salinity makes an important contribution to the density throughout Drake Passage.
}

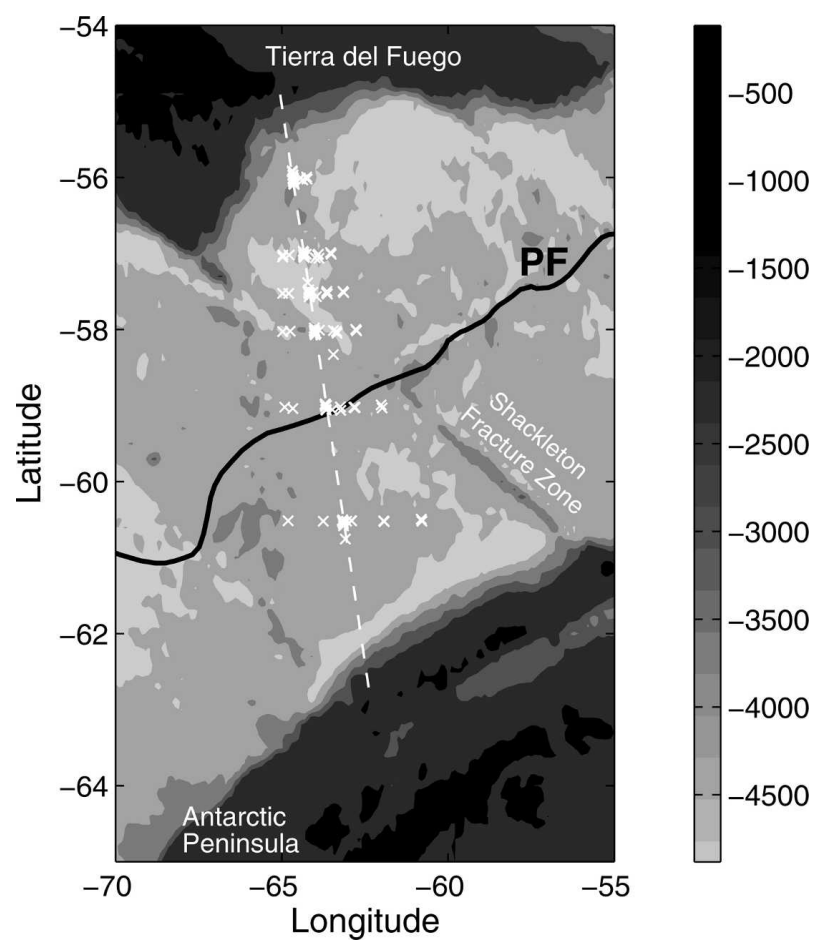

FIG. 1. The position $(\times)$ of each XCTD cast used in the current study. A majority of the casts occur along a single cruise track illustrated by the dashed line. No less than 19 casts were available for analysis at each of six different latitudes. The mean position of the Polar Front from Orsi et al. (1995) is given by the solid line, and the contoured bathymetry $(\mathrm{m})$ is from Smith and Sandwell (1997).

of these casts. While the latitudes of the casts are consistent, the longitude can vary owing to the particular scientific mission of the cruise or inclement weather. Most casts fall along the middle of three typical routes across Drake Passage (Sprintall 2003), indicated by the dashed line in Fig. 1. Profiles of temperature and salinity from casts that deviate from this middle route do not show significant variations from the other casts.

Figure 1 also shows the bathymetry of Drake Passage. XCTDs only sample the upper $1000 \mathrm{~m}$ of the water column and therefore our measurements are well above the sill depth of the major topographical features. The most significant of these features close to our measurement sites is the Shackleton Fracture Zone, which lies to the east of the southernmost casts. Strong internal waves and eddy activity may be generated in this region (Cunningham et al. 2003), but it is unclear if the effects propagate back toward our study area because of the strong eastward ACC. Naveira Garabato et al. (2004) have also found elevated mixing over topography located roughly $500 \mathrm{~km}$ to the west of our current study site and north of the Subantarctic Front. 
It is possible that internal waves generated in this region could radiate toward our measurement sites.

\section{b. Data acquisition and processing}

Data were collected using a Sippican Digital XCTD profiler with a known fall rate. As an XCTD falls through the water column, thermistor resistance and conductivity are relayed back to the ship through a copper wire to the Sippican MK12 data acquisition software. The expendable profilers employ a dual spooling mechanism that decouples the effects of ship roll that affect typical CTDs. The dual spooling mechanism allows XCTDs to be viable tools for observing finescale structure in Drake Passage.

The XCTDs sample to a depth of $1100 \mathrm{~m}$, although the lower $100 \mathrm{~m}$ are prone to error due to wire stretch. The upper $100 \mathrm{~m}$ are also noisy because of weak stratification within the mixed layer. Therefore we present our results for the region between 100 and $1000 \mathrm{~m}$.

We first formed spectra of the raw temperature and salinity profiles and determined a noise floor for each quantity. The salinity was found to be considerably noisier than the temperature profiles because of a mismatch between temperature and conductivity sensors. To eliminate this problem we smoothed the temperature and salinity profiles with triangular filters that had a vertical scale of $1 \mathrm{~m}$ for the temperature profiles and $4 \mathrm{~m}$ for the salinity profiles. ${ }^{2}$ The smoothed temperature and salinity profiles were used to form the potential density profile with density referenced to the surface.

Over much of Drake Passage, only the potential density profiles can be used to determine overturns because of compensated thermohaline intrusions or an unstable temperature stratification. However, south of the Polar Front there is a persistent temperature maximum between 400 and $600 \mathrm{~m}$ below which temperature steadily decreases. In this region stratification is weak, and noise in the salinity profiles can produce large spurious overturns. Therefore, below the temperature maximum we followed Peters et al. (1995) and analyze both density and temperature profiles, only accepting overturns if they are detected in both properties (see discussion below). Visual inspection of the profiles indicates that this is an efficient way to eliminate spurious overturns in weakly stratified regions.

After profiles are reordered to be gravitationally

\footnotetext{
${ }^{2}$ We worried about the effects of smoothing temperature and salinity over different scales, especially because of observed thermohaline intrusions, but our results were essentially unchanged when temperature was smoothed out to the same scale as salinity.
}

stable, overturns are defined to be regions over which the integral of Thorpe displacements is equal to zero (Dillon 1982). The limiting factor in overturn detection is the noise level of the potential density profiles. After detrending and analyzing a number of different sections, the average noise in the XCTDs was determined to be $\delta_{\rho}=0.001 \mathrm{~kg} \mathrm{~m}^{-3}$. Following Galbraith and Kelley (1996), the minimum thickness of a resolvable overturn is given by

$$
L_{\rho_{\text {min }}} \approx 2 \frac{g}{N^{2}} \frac{\delta \rho}{\rho_{0}},
$$

where $\rho_{0}$ is the mean density. Since $N^{2}$ can vary by an order of magnitude over Drake Passage, the resolution size depends strongly on both latitude and depth. Figure 2a shows $N$ and Fig. 2b shows $L_{\rho_{\min }}$ throughout Drake Passage averaged over all casts. In our detection algorithm, each possible overturn must be thicker than $L_{\rho_{\min }}$ (with a minimum size of $4 \mathrm{~m}$, the salinity smoothing scale), and the difference between its maximum and minimum density must be $2 \delta \rho$ before it is accepted as a valid overturn. Over most of Drake Passage, $L_{\rho_{\min }}$ is only slightly greater than $4 \mathrm{~m}$, but south of the Polar Front at depths close to $1000 \mathrm{~m}$, stratification is weak and $L_{\rho_{\min }}$ approaches $20 \mathrm{~m}$. Although Stansfield et al. (2001) show that the largest overturns make the most important contribution to the turbulent dissipation, we may underestimate mixing in very weakly stratified regions if many smaller overturns are discarded.

Galbraith and Kelley (1996) propose two tests, the run-length test and the watermass test, to eliminate spurious overturns. Johnson and Garrett (2004) have since shown that the run-length test is often unreliable for distinguishing between real overturns and noise, and they suggest that Thorpe scale estimates provide an upper bound on mixing rates when the run-length test is not applied. The watermass test is designed to eliminate spurious overturns due to $T-S$ mismatch as occurs with XCTDs. Most $T-S$ mismatch is eliminated by our smoothing procedures. However, we find that most of our overturns are close to or just below the critical value for acceptance proposed by Galbraith and Kelley (1996). Visual inspection of these overturn regions on a $T-S$ diagram does not show the looping structure that is characteristic of $T-S$ mismatch (Galbraith and Kelley 1996). Following Martin and Rudnick (2007), we use a watermass test criterion less strict than Galbraith and Kelley (1996) by a factor of 2. Most overturns that fail our watermass test are found at depth, south of the Polar Front, and are also typically eliminated on the basis of overturns not appearing in both temperature and potential density profiles.

Figure 3 shows examples of typical profiles in the 

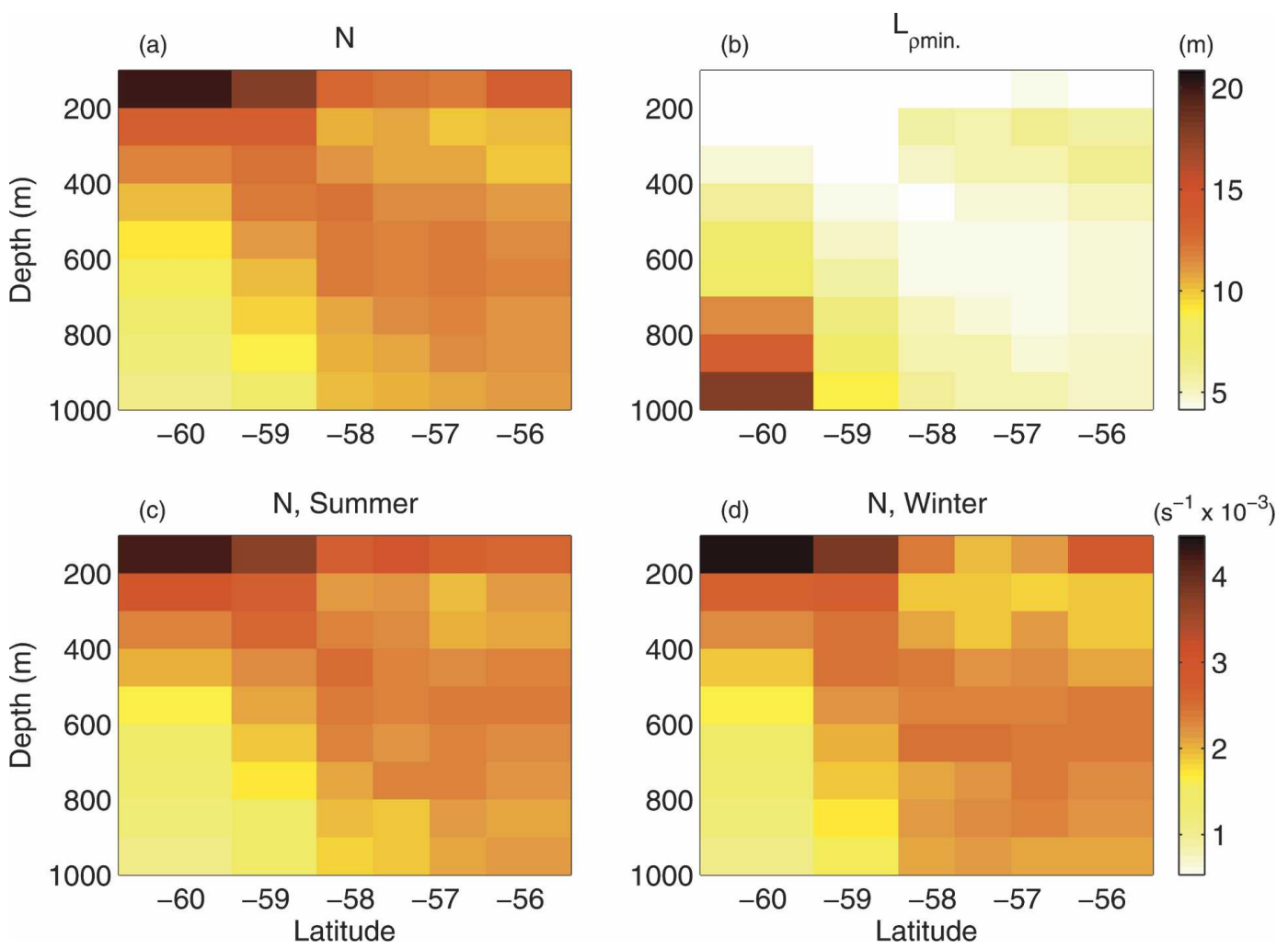

FIG. 2. (a) Buoyancy frequency $N$ divided into 100-m bins and averaged over all casts at each latitude. (b) Minimum resolvable overturn size $L_{\rho_{\min }}$ in each 100-m bin based on (11) using the mean buoyancy frequency in (a) and $\delta_{\rho}=0.001 \mathrm{~kg} \mathrm{~m}^{-3}$. No overturns smaller than $4 \mathrm{~m}$ are accepted owing to our data processing. Buoyancy frequency divided into (c) summer and (d) winter months shows little seasonal signal. The scale is the same in (a), (c), and (d).

northern (upper panels) and southern (lower panels) regions of Drake Passage. The use of temperature profiles to detect overturns is shown at both sites for comparison, but in general this method only modifies mixing rates below the temperature maximum south of the Polar Front. The gray curves in Figs. 3a, 3b, 3f, and $3 g$ are the reordered profiles, while the Thorpe displacements due to potential density (black) and temperature (gray) are shown in Figs. 3d and 3i. The large overturn in density at the bottom of Fig. $3 \mathrm{i}$ is a common feature of southern Drake Passage profiles and is caused by noise in the salinity profile. The resulting values of $L_{T}$ for each accepted overturn are shown in Figs. $3 e$ and $3 \mathrm{j}$. An expanded view of one of the larger overturns in our dataset is shown in Figs. 3f-h.

Initially 5686 possible overturns are detected and, after all tests are applied, 1301 overturns are accepted as real. For each overturn, values for $L_{T}, N$, and $\varepsilon$ are computed (not depth-averaged quantities). Profiles of $L_{T}$ and $\varepsilon$ are constructed that are zero outside of overturns and nonzero within. Profiles of $\kappa_{\rho}$ are computed from (4) using $\varepsilon$ and the background buoyancy fre- quency calculated over 100-m bins. Depth-averaged quantities of $L_{T}, \varepsilon$, and $\kappa_{\rho}$ are computed over the same 100 -m bins following (5), and each bin is averaged over many casts.

\section{c. XCTD noise effects}

Johnson and Garrett (2004) introduce the nondimensional parameters $Q$ and $n$ to describe the two limiting factors of overturn detection: density resolution and vertical resolution. Using values from our study given in Table 1, the amplitude of the noise scaled by the density change over the section is

$$
Q=\frac{\delta \rho}{(d \rho / d z) H}=0.01-0.1,
$$

and $n$ is given by

$$
n=\frac{H}{h} \approx 800,
$$

where $\delta \rho$ is the instrument noise, $d \rho / d z$ is the stratification, $H$ is the section length, and $h$ is the vertical 

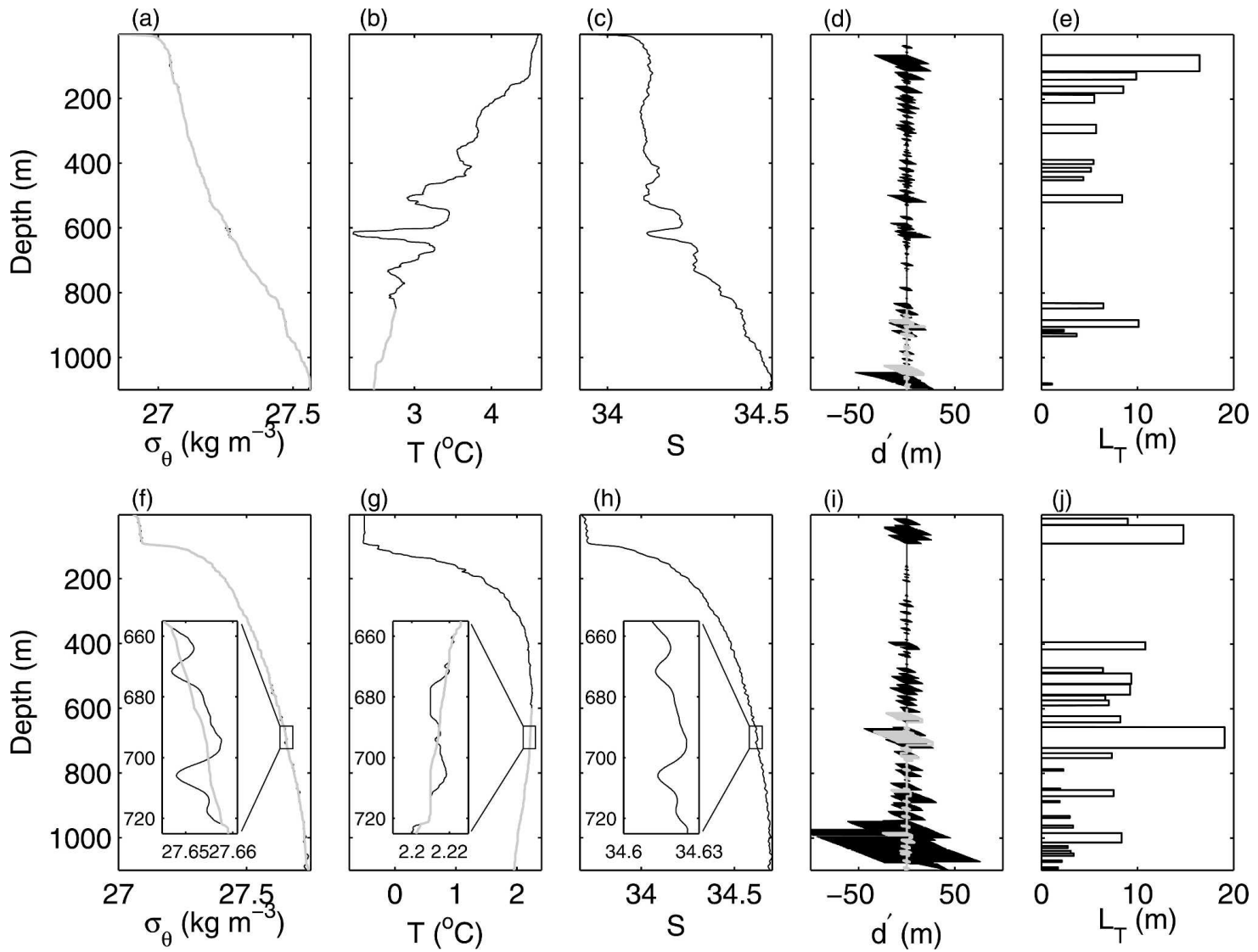

FIG. 3. (a), (f) Potential density, (b), (g) temperature, and (c), (h) salinity profiles at typical profiles north and south of the PF, respectively. The casts were collected at (top) $56^{\circ} \mathrm{S}$ in November 2004 and $60.5^{\circ} \mathrm{S}$ in June 2003. In the potential density and temperature panels the gray thick curve indicates the reordered profile. Temperature is only reordered outside of regions where double-diffusive convection may be important. (d), (i) The Thorpe displacements for both reordered density (black curve) and reordered temperature (gray curve). (e), (j) Each block represents a turbulent overturn whose vertical thickness and horizontal length represents the individual overturn's vertical size and Thorpe scale, respectively. Both (f) and (g) show expanded views of one of the largest overturns in our dataset.

sampling interval. For $n Q>1$, density resolution limits overturn detection (as in our study), while for $n Q<1$, vertical resolution limits overturn detection (Stansfield et al. 2001).
In Table 1 we present values for dimensional and nondimensional noise parameters of different Thorpe scale studies. The studies listed, with the exception of Timmermans et al. (2003), include near-surface mea-

TABLE 1. Noise parameters for various Thorpe scale studies, where $\delta \rho$ is the instrument noise, $d \rho / d z$ is the stratification, $H$ is the depth of the section analyzed, and $h$ is the distance between measurements. Timmermans et al. (2003) used only temperature profiles for overturns so that $\delta \rho$ and $d \rho / d z$ are replaced by $\delta T$ and $d T / d z$. Noise parameters of XCTD temperature profiles in the Pacific are given for comparison. The two GK96 entries are separate datasets analyzed by Galbraith and Kelley (1996), and the two values of $\delta \rho$ from Stansfield et al. (2001) represent two different types of CTDs that were utilized. The nondimensional parameters $Q$ and $n$ are defined in (12) and (13) and discussed in section 3c.

\begin{tabular}{lccrrrr}
\hline \multicolumn{1}{c}{ Study } & $\delta \rho\left(\mathrm{kg} \mathrm{m}^{-3}\right)$ & $d \rho / d z\left(\mathrm{~kg} \mathrm{~m}^{-4}\right)$ & $H(\mathrm{~m})$ & $h(\mathrm{~m})$ & $Q$ & $n$ \\
\hline GK96 (SLE) & 0.001 & 0.09 & 50 & 0.02 & 0.0002 & 2500 \\
GK96 (EUBEX) & 0.001 & 0.0009 & 1000 & 0.25 & 0.001 & 4000 \\
Stansfield et al. (2001) & $0.0006 / 0.004$ & 0.01 & 100 & 0.01 & $0.0006 / 0.004$ & 1000 \\
Finnegan et al. (2002) & 0.0005 & $0.005-0.0001$ & 300 & 0.40 & $0.0003-0.017$ & 750 \\
XCTDs (Drake Passage) & 0.001 & $0.001-0.0001$ & 100 & 0.13 & $0.01-0.1$ & 800 \\
& $\delta T\left({ }^{\circ} \mathrm{C}\right)$ & $d T / d z\left({ }^{\circ} \mathrm{C} \mathrm{m}^{-1}\right)$ & & & & \\
Timmermans et al. (2003) & 0.00013 & 0.001 & 5 & 0.03 & $0.02-0.3$ & $20-200$ \\
XCTDs (Pacific) & 0.005 & 0.01 & 100 & 0.13 & 0.005 & 800 \\
\hline
\end{tabular}




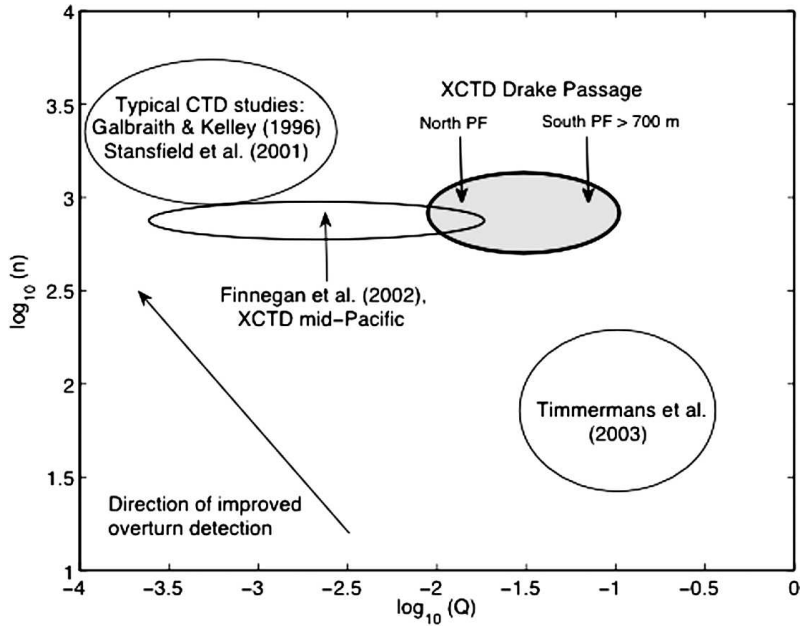

FIG. 4. Diagram of Thorpe scale studies and their associated noise parameters based on Johnson and Garrett's (2004) Fig. 3. The definitions of $Q$ and $n$ are given in (12) and (13). The various studies labeled here are described in Table 1. Overturn resolution improves as $n$ increases and as $Q$ decreases. The current study is given by the shaded oval, with noise parameters north of the PF having smaller values of $Q$ and south of the PF below $700 \mathrm{~m}$ having larger values of $Q$. The Thorpe scale method could not distinguish overturns from noise in Timmermans et al. (2003); we find that overturn detection is marginal below $700 \mathrm{~m}$ south of the PF.

surements similar to ours. Timmermans et al. consider thermohaline staircase structures in the deep Canada Basin and analyze temperature profiles as opposed to density so that $\delta \rho$ and $d \rho / d z$ are replaced by $\delta T$ and $d T / d z$ in Table 1 . Figure 4 illustrates the location of these studies in parameter space. Overturn detection improves as $Q$ decreases and $n$ increases. Johnson and Garrett (2004) find that the studies listed in the upper left corner of Fig. 4 are reliable, whereas true overturns are indistinguishable from noise in the study of Timmermans et al. (2003). The weak stratification of Drake Passage pushes the limits of XCTD overturn detection, which is reflected in our comparatively large values of $L_{\rho_{\min }}$ [cf. Finnegan et al. (2002), where $L_{\rho_{\min }}$ varies between 0.2 and $10 \mathrm{~m}]$. However, as discussed below, we find good agreement between spatial patterns in the Thorpe scale and strain spectral methods. This latter method depends on scales larger than $15 \mathrm{~m}$ that should be unaffected by noise and gives us confidence in our results.

Figure 5a presents the cumulative density function of the total dissipation based on the size of all accepted overturns. The solid vertical line represents the minimum value of $L_{\rho_{\min }}(4 \mathrm{~m})$, the dotted line is the mean value of $L_{\rho_{\min }}$ over Drake Passage $(6.5 \mathrm{~m})$, and the dashed line is the maximum value of $L_{\rho_{\min }}(19.5 \mathrm{~m})$. Figure $5 \mathrm{~b}$ shows that the probability density function of

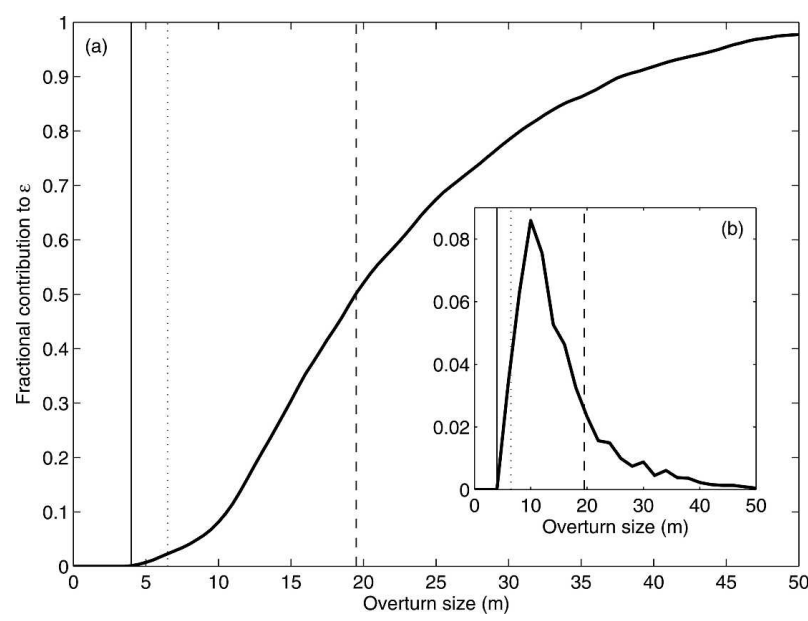

FIG. 5. (a) Cumulative density function of total dissipation $\varepsilon$ based on overturn size and (b) probability density function of overturn size for all accepted overturns. Originally 5686 inversions were detected, and 1301 of these were accepted as true overturns. The solid vertical lines mark the minimum value of $L_{\rho_{\min }}$, the dotted lines mark the mean value of $L_{\rho_{\min }}$, and the dashed lines mark the maximum value of $L_{\rho_{\min }}$ in our study (Fig. 2).

overturn size is lognormally distributed as described by Ferron et al. (1998) and Stansfield et al. (2001). The peak in the distribution occurs between 10 and $12 \mathrm{~m}$. Therefore, if $L_{\rho_{\min }}>12 \mathrm{~m}$, we might expect a significant portion of the overturns to be indistinguishable from noise. Note that $L_{\rho_{\min }}$ exceeds $12 \mathrm{~m}$ in only a small region of our domain (Fig. 2b).

As a final test we analyzed both density and temperature profiles from 20 XCTD casts in the midlatitude South Pacific Ocean and found $\kappa_{\rho}$ values of $O\left(10^{-5}\right.$ $\left.10^{-4} \mathrm{~m}^{2} \mathrm{~s}^{-1}\right)$, comparable to open-ocean levels acquired from microstructure measurements. The parameters for the temperature profiles of these Pacific XCTDs are included in Table 1 and Fig. 4 for comparison.

\section{Results}

\section{a. Drake Passage and the Polar Front}

While the focus of this study is primarily on mixing, the XCTD dataset offers one of the few multiyear surveys of hydrography available in the Southern Ocean. For this reason we briefly comment upon some of the temperature and salinity properties of Drake Passage before discussing our mixing results.

The most striking feature of the XCTD data is that profiles in northern and southern Drake Passage exhibit distinct differences, with the transition between the two regions occurring at the Polar Front (PF). The average position of the $\mathrm{PF}$, taken as the northernmost 

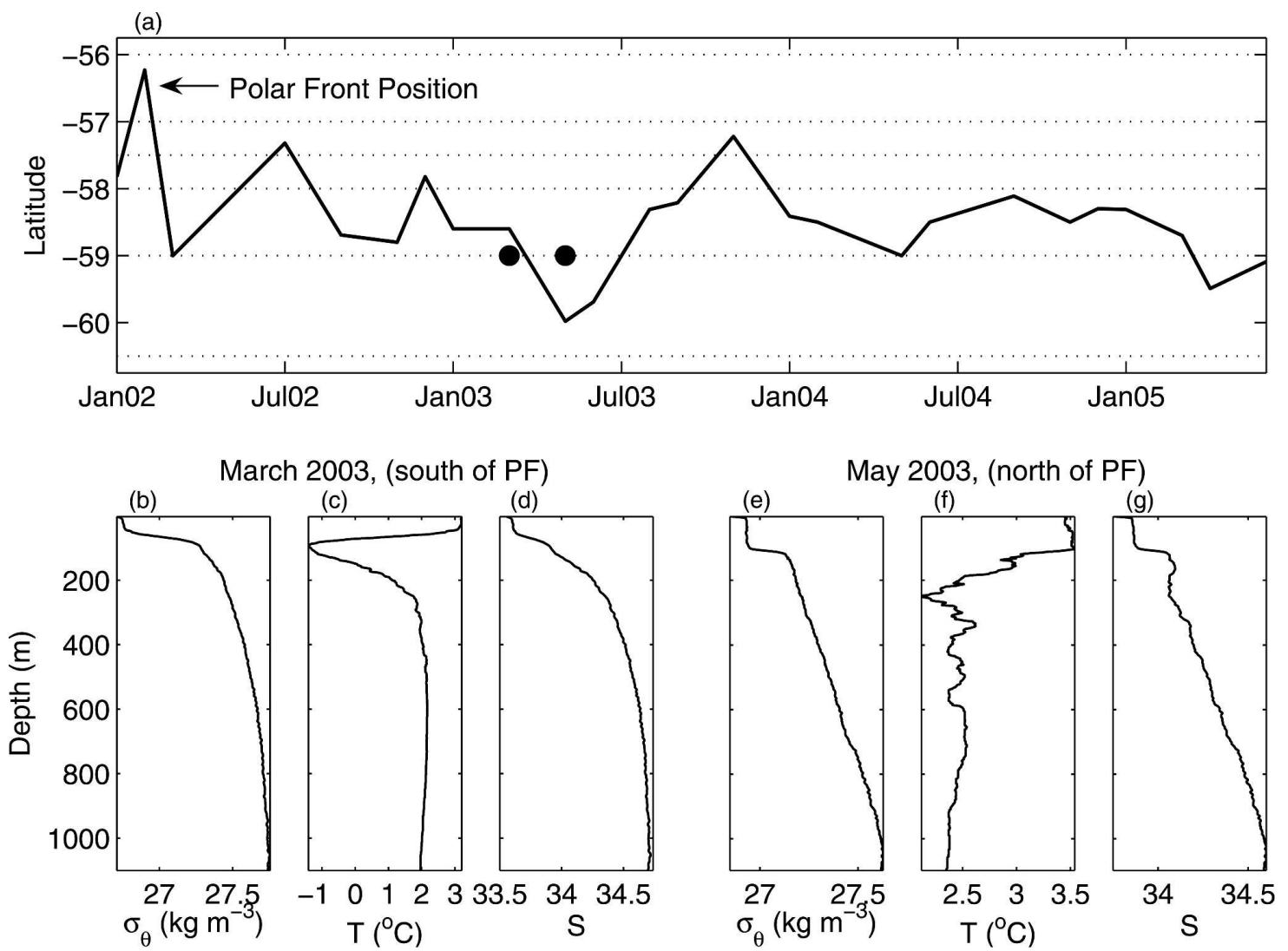

FIG. 6. (a) Position of the Polar Front at 200-m depth as determined from each Drake Passage cruise from 2002 to 2005. Dotted lines indicate the latitudes of XCTD casts. (b)-(d), (e)-(g) The $\sigma_{\theta}, T$, and $S$ at $59^{\circ} S$ at times when the cast was south and north of the PF, respectively. The cruise dates in the bottom panels are marked by dots in (a).

extent of the $2^{\circ} \mathrm{C}$ isotherm at $200 \mathrm{~m}$ (Orsi et al. 1995) and shown in Fig. 1, passes our measurement sites at $58.4^{\circ} \mathrm{S}$, but the instantaneous position of the PF can vary by hundreds of kilometers. Figure 6a shows the position of the $\mathrm{PF}$, as determined by the closely spaced XBTs, for each cruise used in our study. The dotted horizontal lines indicate the measurement latitudes of the XCTDs. To emphasize the importance of the PF transition, we show $\sigma_{\theta}, T$, and $S$ profiles from two casts taken at the same latitude $\left(59^{\circ} \mathrm{S}\right)$ and separated by only 3 months, but taken on different sides of the PF. These two casts show markedly different characteristics despite temporal and spatial proximity.

North of the PF, profiles are characterized by rapid, compensating inversions in temperature and salinity that have a thickness of 20-50 m (Figs. $3 \mathrm{~b}$ and $3 \mathrm{c}$ and $6 \mathrm{f}$ and $6 \mathrm{~g})$. Mesoscale eddy energy is significantly larger north of the PF (Sprintall 2003; Lenn et al. 2005, manuscript submitted to J. Mar. Res.). These eddies give rise to thermohaline intrusions that are persistent features of the northern Drake Passage (Joyce et al. 1978; Toole $1981)$ and give the region its $T-S$ interleaving signature.
South of the PF eddy energy is much lower and there is little deviation between profiles. Temperature in the upper $100 \mathrm{~m}$ varies seasonally, but a sharp minimum consistently occurs near $100 \mathrm{~m}$ (Fig. 6c). Temperature then increases weakly until it reaches a maximum between 400 and $600 \mathrm{~m}$. Below this depth temperature steadily decreases. Although temperature is unstably stratified between the two extrema, the density profile remains stably stratified owing to the salinity field. The unstable temperature and the stable salinity gradients suggest that the water column could be prone to double-diffusive convection, which we discuss further in section $5 b$.

Figure 2a shows buoyancy frequency values averaged over all casts and also divided into winter (AprilSeptember; Fig. 2c) and summer (October-March; Fig. 2d) months. The stratification between 100 and $1000 \mathrm{~m}$ of Drake Passage varies little between winter and summer. Despite the rapid changes in temperature and salinity north of the PF, the buoyancy frequency is roughly constant with $N \approx 2.5 \times 10^{-3} \mathrm{~s}^{-1}$, although at depths between 200 and $400 \mathrm{~m}, N$ is slightly smaller. In 
(a)
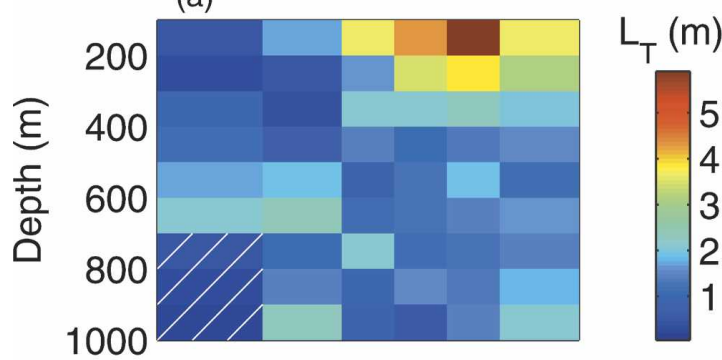

(b)
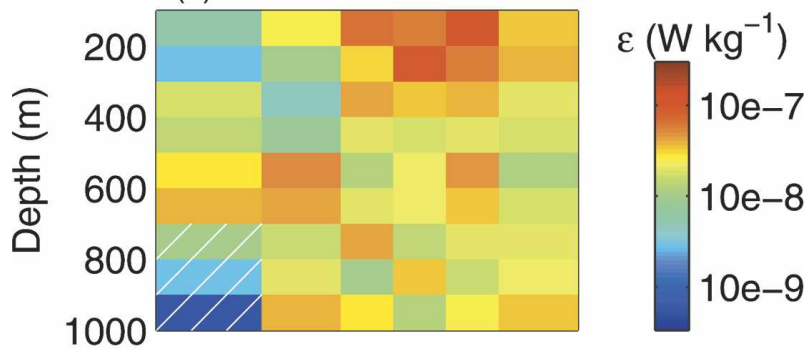

(c)
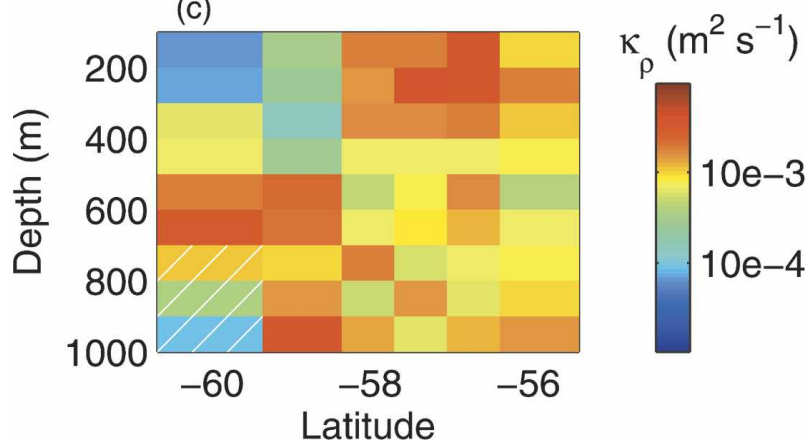

FIG. 7. (a) Thorpe scale $L_{T}$, (b) turbulent dissipation rate $\varepsilon$, and (c) turbulent diffusivity $\kappa_{\rho}$ averaged over $100-\mathrm{m}$ bins for all the casts at each latitude. The crosshatched area indicates regions where stratification is weak and overturn detection is marginal (see section 3c).

contrast, stratification south of the PF decreases monotonically with increasing depth. Over the upper $1000 \mathrm{~m}$, $N$ typically decreases by a factor of 5 .

The sharp change in properties across the PF suggests that different physical processes may govern mixing in these two regions.

\section{b. Thorpe scales}

Along with buoyancy frequency, the Thorpe scale $L_{T}$ is the fundamental quantity from which $\varepsilon$ and, in turn, $\kappa_{\rho}$ are inferred. The depth-averaged value of $\varepsilon$ depends on the number and size of overturns (that pass the criteria in section $3 \mathrm{~b}$ ) as well as the magnitude of $L_{T}$ associated with each overturn.

Figure 7a shows 100-m depth-averaged $L_{T}$ for all casts. In northern Drake Passage, elevated values of $L_{T}$ up to $5 \mathrm{~m}$ are found in the upper 100 to $400 \mathrm{~m}$ and decay away from the surface. The surface-intensified values extend as far south as $58^{\circ} \mathrm{S}$ and are largest near $57^{\circ} \mathrm{S}$. Below $500 \mathrm{~m}_{T}$ is approximately $2 \mathrm{~m}$. In southern Drake Passage, surface values are considerably smaller with $L_{T} \approx 1 \mathrm{~m}$. Rather than decaying with depth, $L_{T}$ increases to a maximum value of roughly $2.5 \mathrm{~m}$ near a depth of $600 \mathrm{~m}$. Below this peak, $L_{T}$ decreases with depth. In Figs. 7 and 8, the crosshatched area indicates a region where $L_{\rho_{\min }}>12 \mathrm{~m}$ (Fig. 2b) and overturn detection is marginal. Overall, our $L_{T}$ estimates are comparable to previous Thorpe scale studies that encountered regions of weak stratification, such as Ferron et al. (1998) and Finnegan et al. (2002).

Figure 8 shows that there is a strong seasonal variation in $L_{T}$. The surface-intensified $L_{T}$ values observed in Fig. 7a are largely due to winter mixing events. The dominant spatial pattern is also clearer in winter months (Fig. 8a), when a relatively quiet region with $L_{T}$ less than $2 \mathrm{~m}$ stretches from the surface in southern Drake Passage to a depth of almost $1000 \mathrm{~m}$ in northern Drake Passage. During summer months (Fig. 8b), Thorpe scale values are more vertically uniform although $L_{T}$ generally remains larger in northern Drake Passage. The middepth maximum in $L_{T}$ in southern Drake Passage is observed in both summer and winter months with a maximum value $L_{T} \approx 3.5 \mathrm{~m}$ occurring at $59^{\circ} \mathrm{S}$ in the summer and shifting to $60.5^{\circ} \mathrm{S}$ in the winter.

c. Thorpe scale estimates of $\varepsilon$ and $\kappa_{\rho}$

Figure $7 \mathrm{~b}$ presents $100-\mathrm{m}$ depth-averaged values of $\varepsilon$ for all casts. Again the dominant spatial pattern indicates enhanced dissipation at the surface in northern Drake Passage and a middepth maximum at latitudes of $59^{\circ}$ and $60.5^{\circ} \mathrm{S}$. Dissipation values span approximately two orders of magnitude ranging from $10^{-7}$ to $10^{-9} \mathrm{~W}$ $\mathrm{kg}^{-1}$. The spatial pattern in $\varepsilon$ is clearer during winter months (not shown). During summer months $\varepsilon$ has a nearly uniform value of $10^{-8} \mathrm{~W} \mathrm{~kg}^{-1}$ across the Passage with the exception of the 100-200-m bins north of the $\mathrm{PF}$ where $\varepsilon$ is slightly larger and the $800-1000$-m bins at $60.5^{\circ} \mathrm{S}$ where $\varepsilon$ is slightly smaller.

Figure $7 \mathrm{c}$ shows $100-\mathrm{m}$ depth-averaged $\kappa_{\rho}$ for all casts; values are determined from $\varepsilon$ and $N$ according to (4). In general $\kappa_{\rho}$ follows the same spatial pattern as $\varepsilon$ although the pattern here is more distinct. Near the surface in northern Drake Passage, $\kappa_{\rho}$ exceeds $10^{-3}$ $\mathrm{m}^{2} \mathrm{~s}^{-1}$ and then decays with depth to a background level of about $4 \times 10^{-4} \mathrm{~m}^{2} \mathrm{~s}^{-1}$. In southern Drake Passage the diffusivities are smaller with minimum rates of $2 \times 10^{-5} \mathrm{~m}^{2} \mathrm{~s}^{-1}$ at $60.5^{\circ} \mathrm{S}$ near the surface and peaking at $2 \times 10^{-3} \mathrm{~m}^{2} \mathrm{~s}^{-1}$ at 500-700-m depth.

Figures $8 \mathrm{c}$ and $8 \mathrm{~d}$ show $\kappa_{\rho}$ divided into winter and 

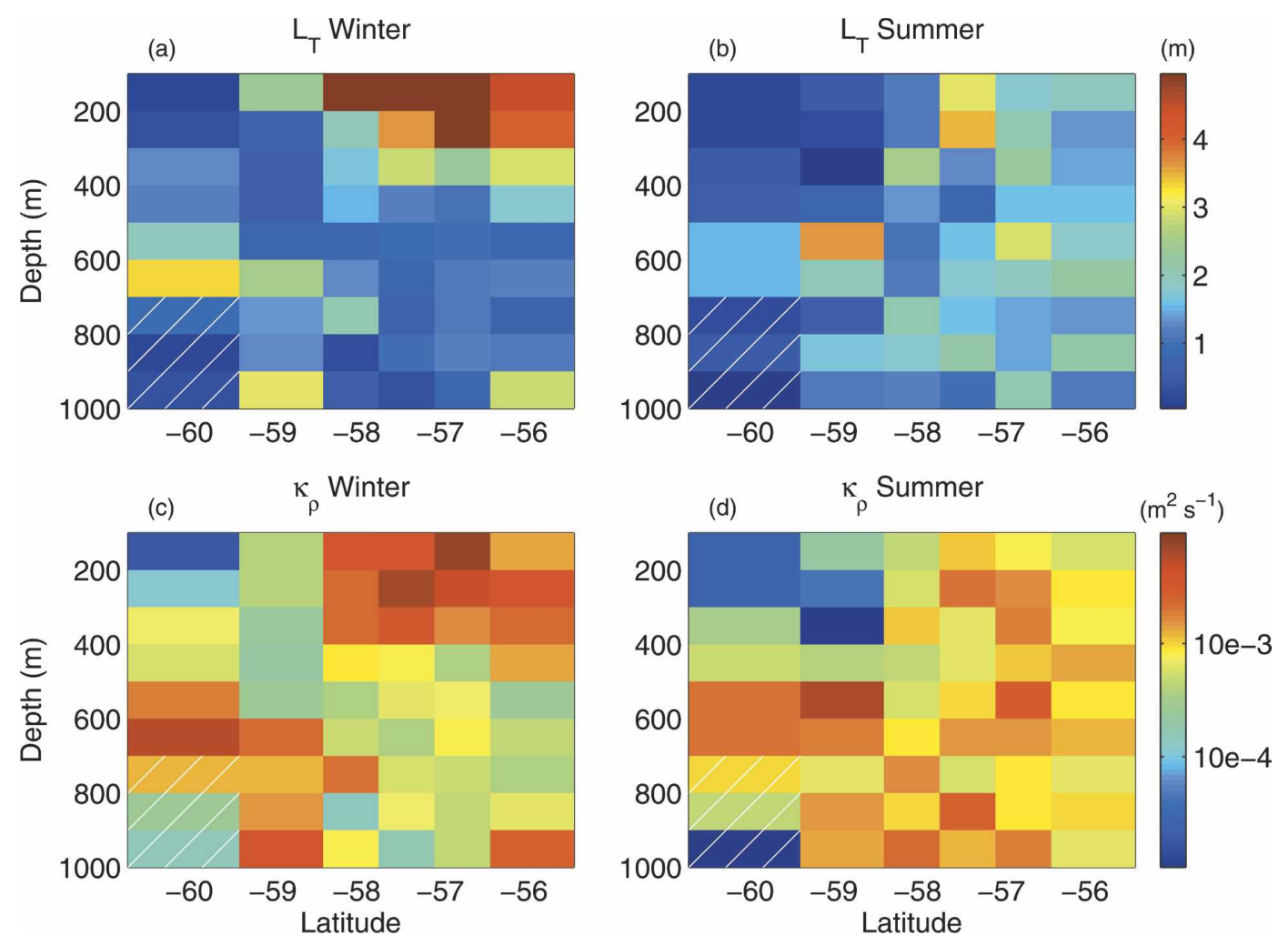

FIG. 8. The 100-m depth-averaged Thorpe scales $L_{T}$ for casts taken during (a) winter (Apr-Sep) and (b) summer (Oct-Mar) months, and 100-m depth-averaged turbulent diffusivity $\kappa_{\rho}$ divided in (c) winter and (d) summer months. The crosshatched area indicates regions where stratification is weak and overturn detection is marginal (see section 3c).

summer months. Again the dominant spatial pattern in $\kappa_{\rho}$ is clearer during winter months. North of the PF, near-surface values of $\kappa_{\rho}$ decrease significantly from winter to summer months while, at depths greater than $400 \mathrm{~m}$, the summer values of $\kappa_{\rho}$ are as large or larger than winter values. The net result is a smoothing of the dominant spatial pattern in the summer.

In Fig. 9 we present $100-\mathrm{m}$ depth-averaged values (thick lines) of $\varepsilon$ and $\kappa_{\rho}$ for all casts collected south of the PF (Figs. 9a,c) and north of the PF (Figs. 9b,d). As described above, a pattern of surface-elevated mixing north of the PF is clearly shown, as is the trend of increasing mixing with depth to $600 \mathrm{~m}$ south of the PF. Again, the PF appears to delineate regions of differing mixing patterns. In each $100-\mathrm{m}$ bin the outer vertical lines represent statistical uncertainty based on the bootstrap method (Efron and Gong 1983). ${ }^{3}$

\footnotetext{
${ }^{3}$ Values of $\varepsilon$ and $\kappa_{\rho}$ were binned into 100 -m intervals. These binned profiles were subsampled and averaged 100 times using one-half of the available data in each bin. The error bars in Fig. 9 represent the $3 \mathrm{~d}$ and 97 th percentiles of the resulting distribution. We use 75 casts collected north of the PF and 39 casts collected south of the PF.
}

The values of $\varepsilon$ and $\kappa_{\rho}$ shown in Figs. 7-9 are larger than typically observed open-ocean subthermocline background levels, although they remain smaller than elevated mixing rates observed above rough topography (as in Drake Passage; Naveira Garabato et al. 2004) and over sills (as in the Romanche Fracture Zone; Ferron et al. 1998). However, open-ocean comparisons may be inadequate because of the unique characteristics of Drake Passage, such as strong zonal flow and strong mesoscale eddy activity (Lenn et al. 2005, manuscript submitted to J. Mar. Res.). The dynamic pathways between eddies and turbulent dissipation are not well understood, but it has been suggested that eddies may enhance mixing (K. L. Polzin 2005, personal communication). Further discussion appears in section $5 \mathrm{~b}$. In the following section we present an alternative method of inferring $\kappa_{\rho}$ to help verify these results.

\section{d. Strain rate estimates of $\kappa_{\rho}$}

Kunze (2003) calculates strain spectra from profiles of buoyancy frequency and the vertical derivative of potential temperature. While the buoyancy frequency estimate can be sensitive to salinity variations where stratification is weak, temperature-inferred strain is not 

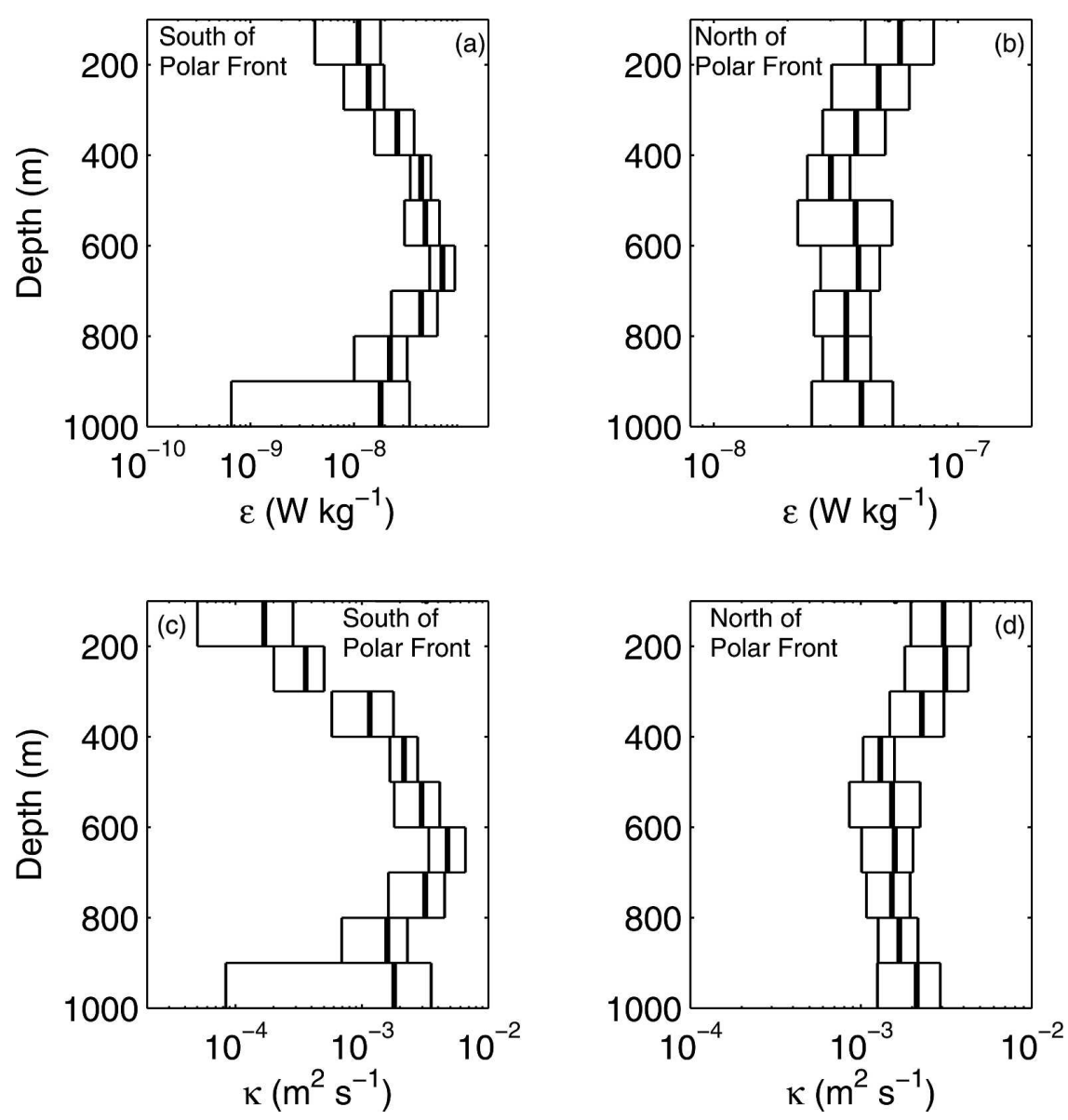

FIG. 9. Turbulent dissipation rate $\varepsilon$ averaged over 100-m bins for all casts (a) south and (b) north of the Polar Front. The 100-m depth-averaged turbulent diffusivity $\kappa_{\rho}$ for all casts (c) south and (d) north of the PF. In each 100-m bin, the width determined by the two outer vertical lines represents statistical uncertainty as determined by a bootstrap technique (Efron and Gong 1983; see footnote in section 4c).

expected to work well in regions where finestructure water-mass variability, such as thermohaline intrusions and interleaving, is strong. Since interleaving is a distinctive feature of Drake Passage, it is not surprising that temperature-inferred strain produce $\kappa_{\rho}$ estimates significantly larger than the buoyancy frequency estimates. As an alternative, Finnegan et al. (2002) analyze strain spectra initially formed from displacement profiles of potential density. We find that both the buoyancy frequency profiles and the displacement profiles give spectra with the same amplitude to within $15 \%$, and, more important, they show the same spatial distribution of mixing across Drake Passage. ${ }^{4}$

\footnotetext{
${ }^{4}$ The spectra plotted in Fig. 10 are based on the buoyancy frequency profiles. These were chosen because there is less noise at high wavenumbers, although we note that this does not affect our mixing rate estimates, which depend on strain variances at low wavenumbers.
}

We divide the data into 200-m segments so that there are no large changes in buoyancy frequency within each bin. The uppermost segment is taken to start at $150 \mathrm{~m}$ in order to exclude the mixed layer, which can give anomalously large strain variances. All other segments begin at multiples of $100 \mathrm{~m}$, so they are half overlapping. To determine strain we first remove a linear trend, then normalize the result by the mean buoyancy frequency over each segment. Spectra at each latitude and from each depth are averaged over all casts.

Figure 10 shows spectra from two different latitudes and at various depths. Our vertical wavenumber spectra for strain agree well with the GM model (thick curve) with a flat region at intermediate wavenumbers that rolls off to a slightly red spectra at the highest resolved wavenumbers. The left-hand panels show spectra from casts taken exclusively north of the PF at $56^{\circ} \mathrm{S}$, while the right-hand panels are from $60.5^{\circ} \mathrm{S}$, exclusively south of the PF. The strain variance ratios are 
$56^{\circ} \mathrm{S}$
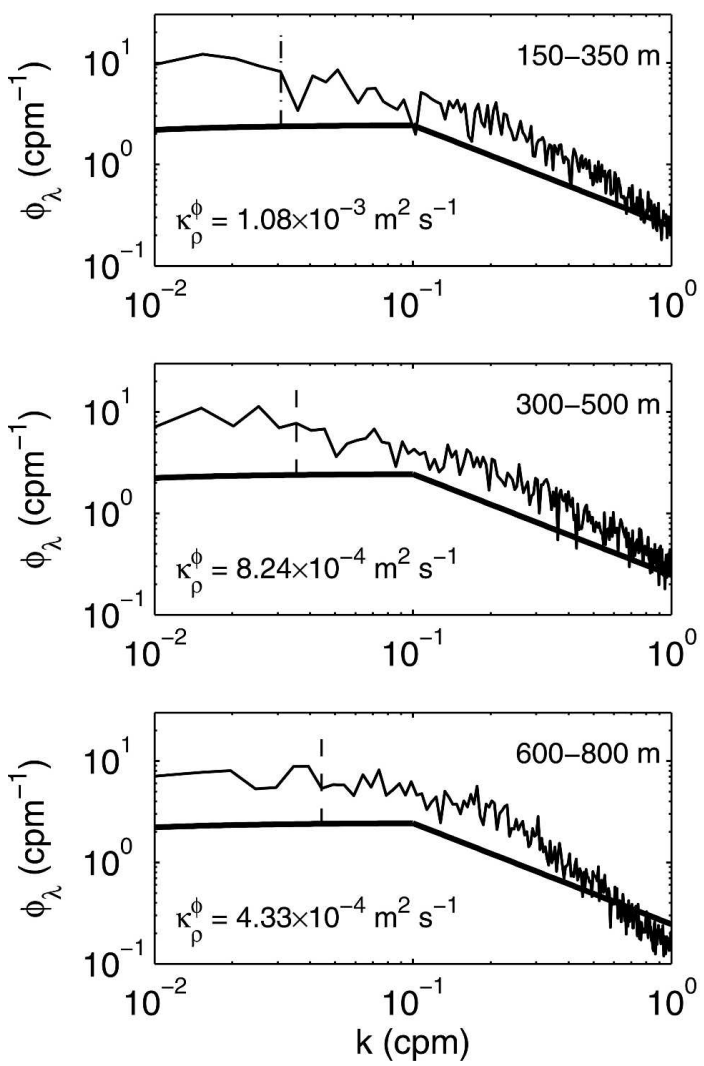

$60.5^{\circ} \mathrm{S}$
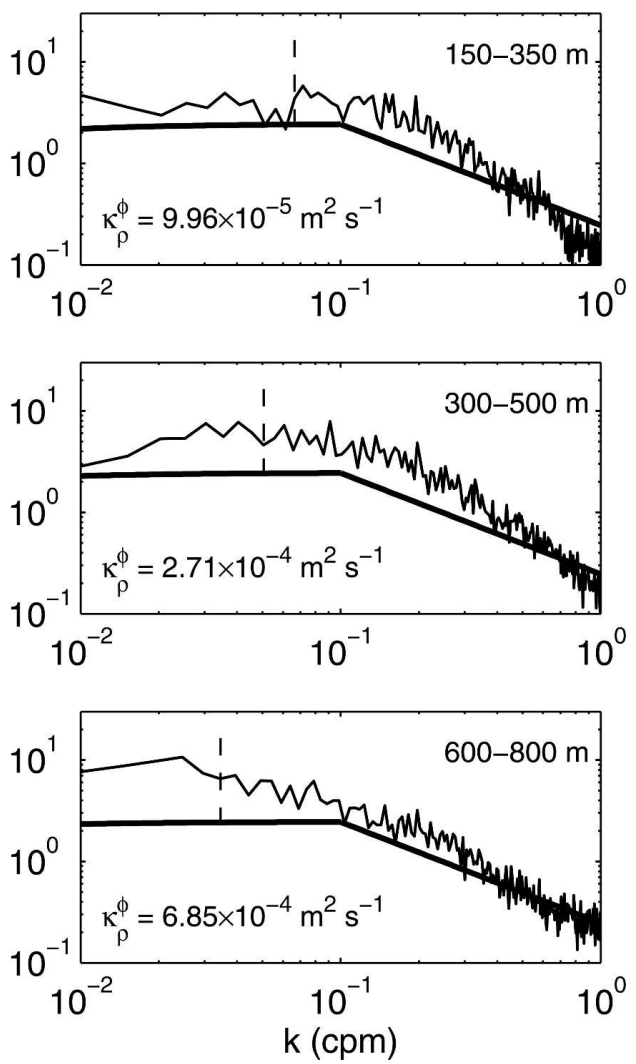

FIG. 10. Vertical strain spectra formed from the buoyancy frequency over 200-m bins as compared with the Garrett-Munk model spectra (thick line). The spectra represent averages over all casts at a given latitude and bin. (Left: casts at $56^{\circ} \mathrm{S}$, which were always north of the PF; right: casts at $60.5^{\circ} \mathrm{S}$, which were always south of the PF.) The vertical dashed line represents the value of $k_{\max }$ as described in (6) with $k_{\min }=0.01$. The accompanying value of $\kappa_{\rho}^{\phi}$, the turbulent diffusivity as calculated from (8), appears in each panel.

determined by integrating both the measured spectra and the GM spectra from $k_{\min }=0.01$ out to $k_{\max }$ as described in (6). The value of $k_{\max }$ is given in each panel by the dashed vertical line. Figure 10 shows that the amplitude of the strain spectra decreases with depth at locations north of the PF, while the amplitude increases with depth at locations south of the PF. The vertical eddy diffusivity based on the strain spectral analysis $\kappa_{\rho}^{\phi}$ is computed using the formula in (8), where we have taken $\mathcal{H}\left(R_{\omega}\right) \mathcal{I}(f, N)=5$ based on the discussion in section $2 \mathrm{~b}$. The corresponding value of $\kappa_{\rho}^{\phi}$ is given in each panel.

Figure 11a shows a representation of $\kappa_{\rho}^{\phi}$ for all casts. The spatial pattern found using the Thorpe scale method remains the dominant feature. Mixing rates are elevated near the surface north of the PF, whereas mixing rates tend to be larger below the surface south of the PF. Although still present, the middepth maximum in mixing south of the PF is not as clearly defined in the strain rate estimate primarily because $\kappa_{\rho}^{\phi}$ does not decrease rapidly below the temperature maximum as $\kappa_{\rho}$ does in the Thorpe scale analysis. Also, $\kappa_{\rho}^{\phi}$ spans a smaller range of values than $\kappa_{\rho}$ (Fig. 7c).

Figure $11 \mathrm{~b}$ gives the ratio of $\kappa_{\rho}$ to $\kappa_{\rho}^{\phi}$. Throughout Drake Passage the Thorpe scale estimate is generally larger than the strain estimate. This suggests that the Thorpe scale estimate may provide an upper bound on mixing rates (see discussion in section $3 b$ ). Over most regions of Drake Passage the ratio of the two estimates is roughly 2-3 and only exceeds 5 in one bin at $59^{\circ} \mathrm{S}$. Because of the assumptions that go into both the Thorpe scale and strain spectral methods, specifically the reliance on numerical constants $R_{\omega}$ and $L_{T} / L_{O}$, there appears to be relatively good agreement between the two methods. The fact that both methods exhibit the same spatial pattern suggests that the dominant contribution to overturning is internal wave breaking.

\section{Discussion}

The results of the previous section provide evidence that mixing events north and south of the PF are distinctly different. Mixing estimates from both Thorpe 

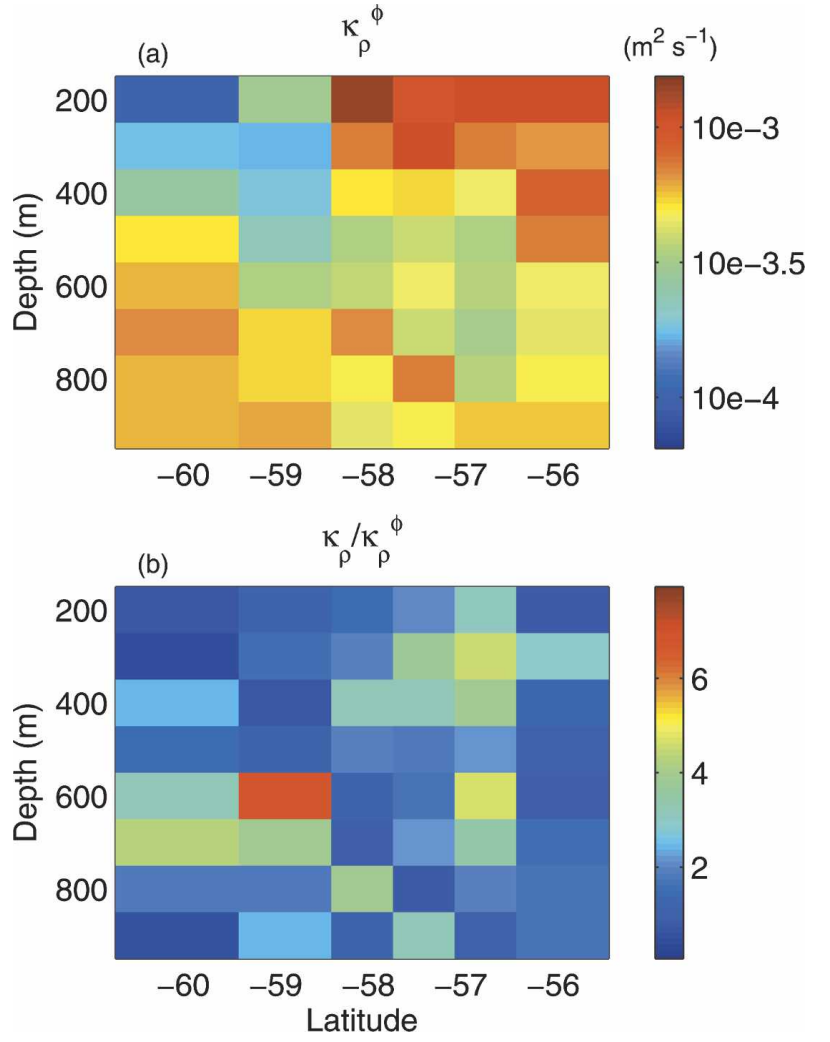

FIG. 11. (a) Turbulent diffusivity as calculated from the vertical strain rate $\kappa_{\rho}^{\phi}$ following the discussion in section $2 \mathrm{~b}$. The data are divided into 200-m half-overlapping bins and represent an average over all casts at each latitude. (b) Ratio of $\kappa_{\rho}$ as derived from the Thorpe scale method to $\kappa_{\rho}^{\phi}$ calculated from the vertical strain rate.

scale and strain rate methods most likely reflect internal wave breaking. However, the spatial and seasonal mixing patterns are also correlated with distinct patterns in winds, thermohaline intrusions, and mesoscale eddy activity across Drake Passage. In this section we discuss the implications of these different processes.

\section{a. Winds}

Large diffusivity values near the surface in northern Drake Passage suggest that winds influence mixing in this region. In a steady-state ocean (which may not be a particularly accurate model for the Southern Ocean), the rate of energy input by wind must be equal to the turbulent dissipation. Wunsch's (1998) study of the wind work on the general ocean circulation shows that the total energy input is dominated by Southern Ocean winds. Local dissipation of this energy would help to support the high mixing rates that we observe in Drake Passage. While Wunsch (1998) considers the role of low-frequency wind work on the general circulation, Alford (2001) describes how higher-frequency fluctuations in the winds can generate inertial motions in the mixed layer that propagate downward as near-inertial internal waves and eventually break, causing smallscale mixing. This second process is more likely to explain the spatial patterns and the seasonality of the upper-ocean mixing signal. Alford (2003) notes that his turbulent dissipation values for the Southern Ocean are likely underestimated because data-poor high-southernlatitude winds from the National Centers for Environmental Prediction are unreliable.

To study the wind's influence on mixing in Drake Passage, we analyze Quick Scatterometer (QuikSCAT) mean wind fields obtained from European Remote Sensing Satellite Processing and Archiving Facility (CERSAT) at the French Research Institute for Exploitation of the Sea (IFREMER) (see online at http://www.ifremer.fr/ cersat). The winds are computed from the National Aeronautics and Space Administration SeaWinds scatterometer and are provided as monthly averages on a global $0.5^{\circ} \times 0.5^{\circ}$ resolution geographical grid. Over our study period, both wind speed and wind stress exhibit the same spatial and seasonal patterns. We present the wind stress data here because the energy flux input by wind is proportional to $\tau \cdot \mathbf{u}$, where $\tau$ is the wind stress and $\mathbf{u}$ is the current velocity.

Figure 12a shows the average wind stress in Drake Passage for all months between January 2002 and July 2005. Strong winds give rise to a large wind stress west of the southern tip of South America. The strong eastward flow of the ACC may advect near-inertial waves formed in this region toward our study site. Wind stress decays moving eastward into our study site. Figure $12 \mathrm{~b}$ presents wind stress data along the mean cruise track (given by the dashed line in Fig. 12a) averaged over all months as well as winter (April-September) and summer (October-March) months. Along the cruise track, wind stress peaks just south of $57^{\circ} \mathrm{S}$ and has a minimum near $59.5^{\circ} \mathrm{S}$. The locations of the wind stress extrema correspond well with the locations of extrema in our surface values of $\kappa_{\rho}$ (Fig. 7c). These results complement the hydrography by providing further evidence that the region north of the $\mathrm{PF}$ is more energetic than south of the PF.

The seasonal change in wind stress amplitude is roughly uniform across Drake Passage despite our observations of a seasonal mixing signal north of the PF (Fig. 8). We expect that storms produce the greatest energy flux into the surface layer, therefore wind stress variance may provide a better indicator of the wind's influence on mixing. Figure 13 plots wind stress variance along the mean cruise track using 12-h QuikSCAT winds from summer and winter months between January 2002 and July 2005. In agreement with Gille (2005), we find that the magnitude of the wind stress variance 

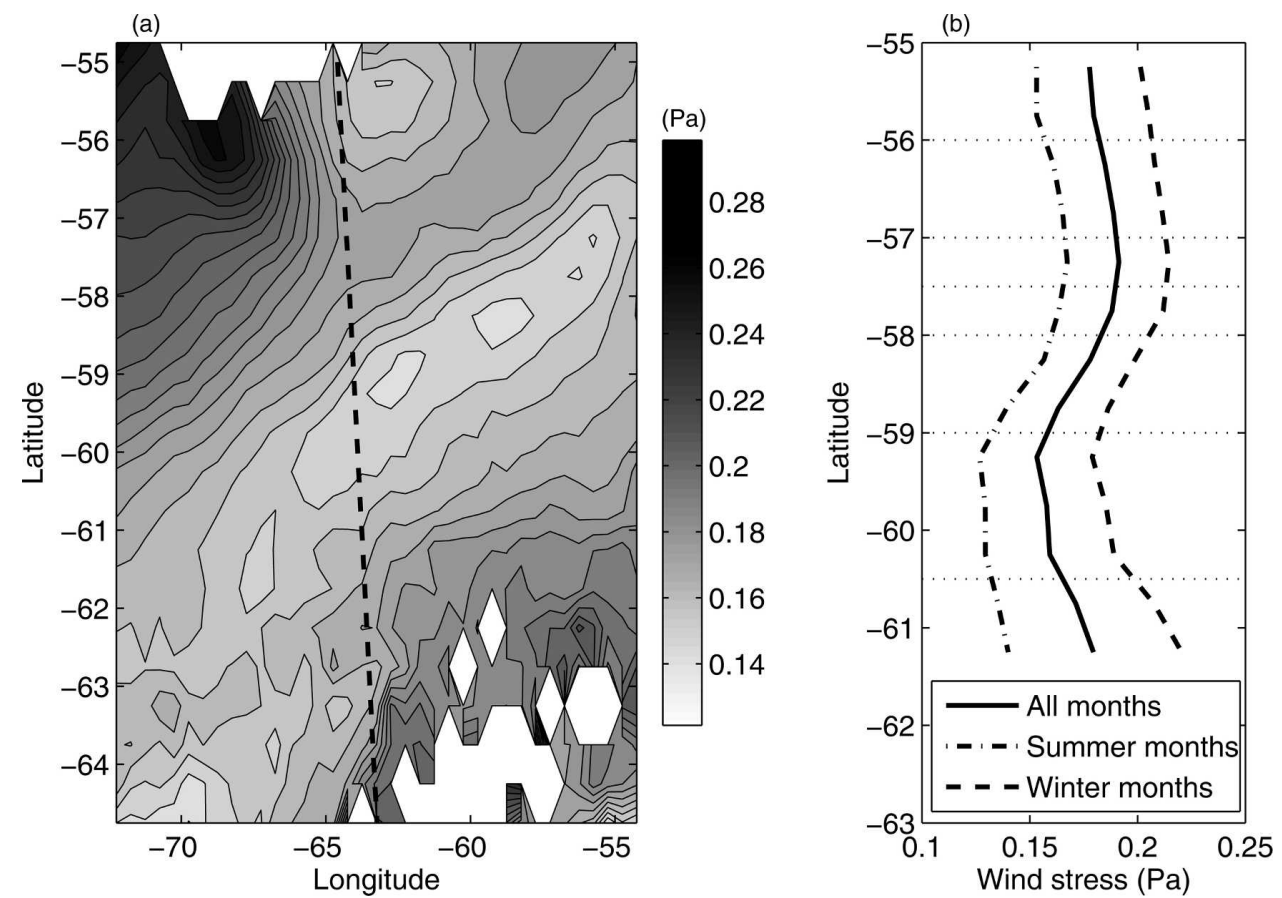

FIG. 12. (a) Average wind stress from QuikSCAT data for all months between January 2002 and July 2005. The dashed line gives the position of the mean cruise track. (b) Average wind stress along the mean cruise track for all months (solid line) and also divided into summer (dash-dot line) and winter (dashed line) months. The dotted lines give the mean latitudes of the measurement sites.

increases significantly during winter months throughout Drake Passage. During summer, wind stress variance is nearly uniform across Drake Passage, whereas during winter months there is a clear peak in variance at the northern measurement sites (indicated by the dotted lines). This provides a possible explanation for the seasonal signal in $\kappa_{\rho}$ north of the PF.

\section{b. Other possible mixing mechanisms}

\section{1) NoRTH OF THE PF}

Observations of compensating interleaving in temperature and salinity (Figs. 3b,c and 6f,g) suggest that thermohaline intrusions play an important role in the dynamics of Drake Passage. Toole (1981) points out that in Drake Passage intrusions are typically confined to the upper $1000 \mathrm{~m}$. Therefore our XCTD casts capture the region of strongest thermohaline variability. Thermohaline intrusions are associated with double diffusive convection, which may represent an alternative source of mixing. While thermohaline intrusions can be driven by both fingering (Ruddick and Turner 1979) and diffusive (Thompson and Veronis 2005) interfaces, fingering convection tends to be more vigorous.

Focusing on casts north of the PF, we analyze 60 prominent cases of $T-S$ interleaving and determine the density ratio for each of these possible intrusions. We select the region of the intrusion where the $T-S$ profiles are susceptible to fingering (i.e., $T$ is the stabilizing component), in which case the density ratio is defined by $R_{\rho} \equiv \alpha \Delta T / \beta \Delta S$. Here $\Delta T$ and $\Delta S$ are the $T$ and $S$ differences over the region where $S$ is unstably stratified, and $\alpha$ and $\beta$ are local coefficients of expansion for $T$ and $S$, respectively. Mean values of $\alpha$ and $\beta$ for each intrusion are calculated using the 1980 Equation of State for Seawater (Fofonoff and Millard 1983). Over these 60 interleaving regions we find that $R_{\rho}$ has a mean value of 1.46 with a standard deviation of 0.29 . The mean thickness of the regions that we analyze is $23.5 \mathrm{~m}$, and the maximum thickness is $50 \mathrm{~m}$.

Fingering convection becomes stronger as $R_{\rho}$ approaches 1 . Our values for $R_{\rho}$ suggest that thermohaline intrusions in this region may, in places, exhibit strong fingering and could be a source of diapycnal mixing. However, strong zonal flow, eddies, and internal waves may act to disrupt finger structures making it difficult to calculate vertical fluxes. Walsh and Ruddick (2000) show that turbulence significantly alters the growth and formation of intrusions as well as the associated fluxes of heat and salt. Larson and Gregg (1983) hypothesize that near-inertial waves aid in intrusion formation, which may also point to strong internal wave activity north of the PF.

There is no observational evidence that eddies en- 

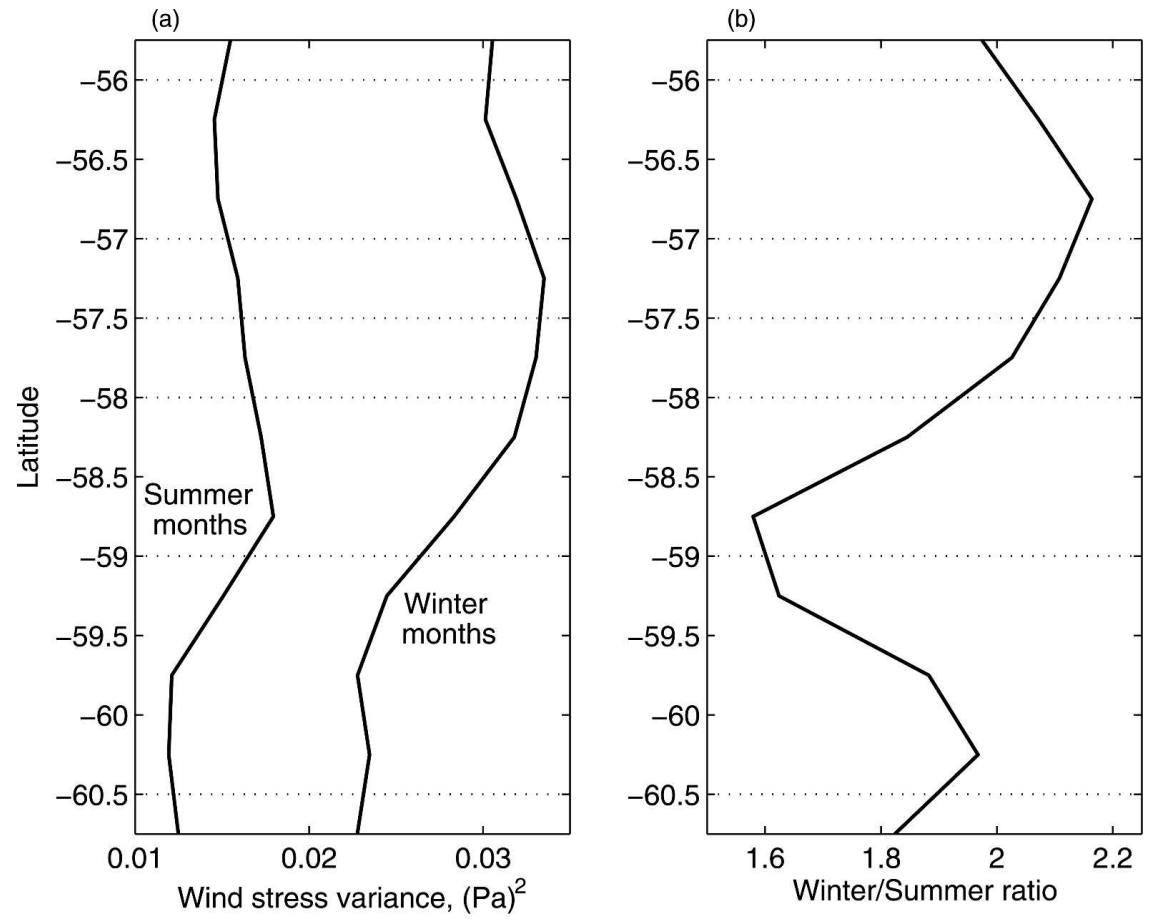

FIG. 13. (a) Wind stress variance from twice-daily QuikSCAT data along the mean cruise track divided into winter (Apr-Sep) and summer (Oct-Mar) months. (b) Ratio of the wind stress variance during winter and summer months that shows a clear peak near $57^{\circ} \mathrm{S}$. The dotted lines give the mean latitudes of the measurement sites.

hance diapycnal mixing; still, they have a large influence on Drake Passage dynamics north of the PF. The ability of Drake Passage eddies to stir large-scale $T-S$ gradients and form thermohaline intrusions is discussed by Garrett (1982). The intrusions are assumed to generate fingering convection from which Garrett (1982) calculates a diapycnal diffusivity. This primitive model predicts $\kappa_{\rho}$ to be an order of magnitude smaller than that inferred from the internal wave field. Ferrari and Polzin (2005) consider similar dynamics in the North Atlantic and suggest that a better understanding of the processes that arrest interleaving could determine whether mesoscale eddies enhance mixing.

While the possibility exists that thermohaline intrusions, mesoscale eddies, and internal waves interact in complicated ways to enhance mixing, these dynamics are poorly understood. Still, all these processes indicate that the region north of the PF is more energetic than south of the PF. The complete lack of interleaving south of the PF indicates that physical processes governing mixing in this region are potentially very different.

\section{2) South of THE PF}

South of the PF, $T$ and $S$ stratification in the upper $500 \mathrm{~m}$ of the water column is susceptible to the diffusive regime of double-diffusive convection (Figs. 3f-j). The $T-S$ profiles in this area are similar to profiles collected in eastern and central Weddell Sea where thermohaline staircases form (Muench et al. 1990). Staircase structures, however, are not apparent in the Drake Passage dataset. It is possible that the resolution of the XCTDs is unable to capture this behavior, although it is more likely that conditions, such as the region's proximity to large topographic features, strong currents, and frontal systems, are unfavorable for staircase formation.

We calculate $R_{\rho} \equiv \beta \Delta S / \alpha \Delta T$, which by convention is the inverse of the fingering case so that $R_{\rho}$ is always $\geq 1$. Here $\Delta T$ is the difference between the $T$ minimum near the surface and the middepth $T$ maximum; $\Delta S$ is the $S$ change over the same depth. Averaging over all casts with similar profiles, we find that $R_{\rho}=2.66$ with a standard deviation of 0.50 . This value is larger than those reported in the Weddell Sea where $R_{\rho}=1.52$ and 1.36 in regions of stronger and weaker temperature gradients, respectively (Muench et al. 1990). Mixing is enhanced as $R_{\rho} \rightarrow 1$, so our value suggests that doublediffusive convection is generally weak. When $R_{\rho}$ exceeds 3 , thermohaline staircases are unlikely to form (Muench et al. 1990).

Howard et al. (2004) suggest a method for determin- 


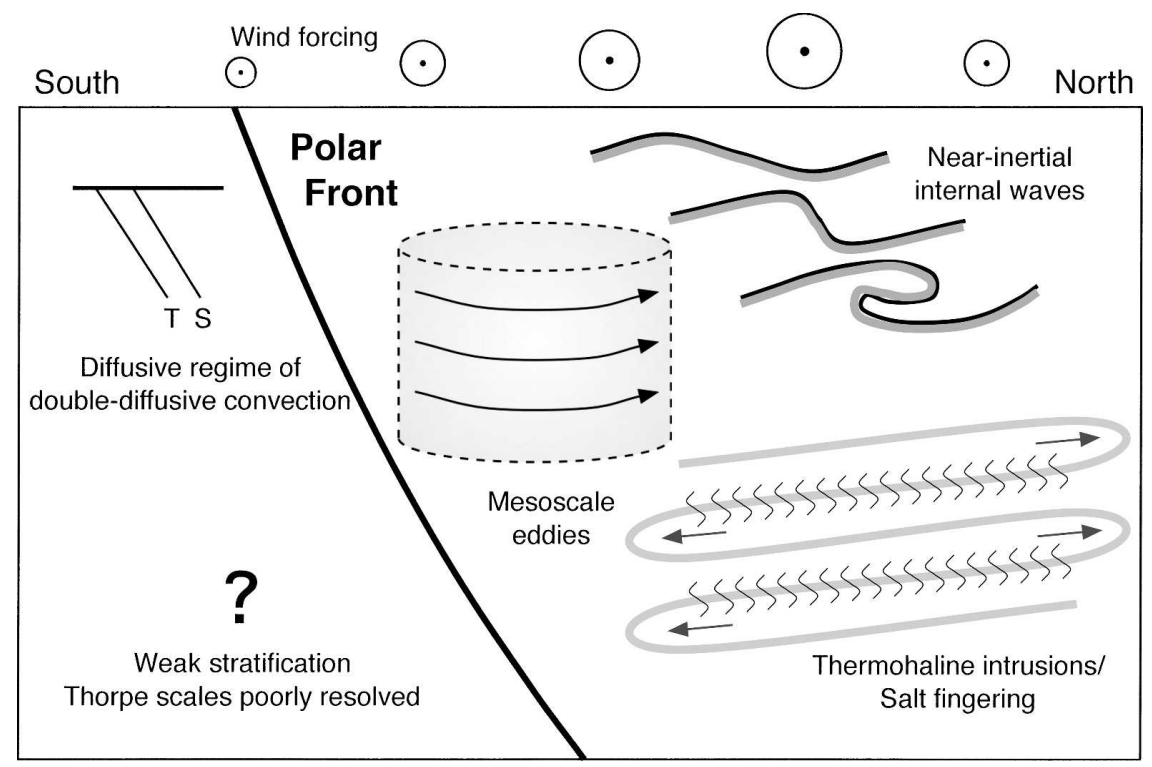

FIG. 14. Schematic of possible mixing processes in Drake Passage. The Polar Front (depicted schematically here) divides two very different regions. North of the PF, strong wind forcing generates near-inertial internal waves that transfer energy to small scales. These waves can break causing small-scale mixing. Thermohaline intrusions are also prevalent north of the $\mathrm{PF}$ and may enhance mixing through salt fingering. Mesoscale eddy activity is large north of the $\mathrm{PF}$, although the role of eddies in vertical mixing processes is not well understood. Near the surface south of the PF, temperature and salinity profiles are susceptible to the diffusive regime of double-diffusive convection and mixing is weak. South of the front mixing increases to a depth of at least $600 \mathrm{~m}$. Below this depth stratification is weak and our mixing estimates are poorly constrained.

ing diapycnal diffusivities in the absence of staircases; however, the fluxes derived from this technique are swamped by the turbulent mixing inferred from the Thorpe scale and strain rate. It is intriguing that Muench et al. (1990) observe a sharp increase in eddy diffusivity near the local $T$ maximum, with $\kappa_{T}$ exceeding $10^{-3} \mathrm{~m}^{2} \mathrm{~s}^{-1}$. Both our Thorpe scale and strain spectral methods predict an increase in $\kappa_{\rho}$ near the $T$ maximum south of the PF. The fact that double diffusion alone cannot describe mixing south of the PF is, perhaps, not surprising since wind forcing and eddy activity, while smaller south of the PF, are still elevated above levels in midlatitude oceans.

\section{Summary and open questions}

In this paper we use two independent techniques to calculate turbulent mixing rates in the upper $1000 \mathrm{~m}$ of Drake Passage from expendable CTD probes. Uncertainty in the magnitude of our dissipation $\varepsilon$ and diffusivity $\kappa_{\rho}$ estimates may arise from our choice of certain numerical constants (see section 2). Furthermore, the theoretical basis for both the Thorpe scale and internal wave vertical strain techniques is subject to a number of assumptions that are not well tested in energetic regions like Drake Passage. Therefore, our main conclusions focus on the identification of robust mixing patterns that appear in the two analyses.

The Polar Front delineates two regions governed by different physical processes. Profiles collected north of the PF are dominated by compensated interleaving, whereas strong interleaving is absent from all profiles collected south of the PF. The clearest spatial signal that we observe is an order of magnitude decrease in surface (upper $400 \mathrm{~m}$ ) mixing rates moving from north to south across the PF. The clearest seasonal signal occurs in surface values north of the PF with mixing rates larger in the winter. Mixing rates decay weakly with depth north of the PF. South of the PF mixing increases steadily with depth and peaks near the local temperature maximum. Mixing rates below the temperature maximum are not well constrained because overturn detection becomes marginal. Where overturns are well resolved, our Thorpe scale estimates are consistently larger by a factor of 2-3 than those obtained from the strain spectral method. Strain spectral estimates, which parameterize mixing caused by internal wave breaking, could underestimate mixing 
rates if other processes, such as salt fingering, make a similar contribution to the dissipation. However, we suspect that the dominant contribution to mixing is internal wave breaking, and Thorpe scale estimates provide an upper bound on mixing rates (see discussion in section $3 b$ ).

Figure 14 summarizes some possible mechanisms that may influence the spatial and temporal mixing patterns that we observe. Wunsch (1998) indicates that the largest energy input to the oceans due to low-frequency wind work occurs in the Southern Ocean, which may lead to large turbulent dissipation rates. Energy input from high-frequency winds can form near-inertial internal waves that eventually transfer their energy to small scales when they break. In our study, elevated mixing rates near the surface are found at latitudes corresponding to peaks in both wind stress and wind stress variance. Also, seasonal variations in wind stress variance and diapycnal diffusivities are largest north of the PF. Double-diffusive processes may also contribute to mixing in Drake Passage. The strong interleaving found north of the PF suggests that thermohaline intrusions, which give rise to salt fingering, are prevalent. Weaker mixing may occur because of the diffusive regime of double-diffusive convection in regions where temperature is unstably stratified south of the PF. Perhaps the most distinguishing feature of Drake Passage is the persistent influence of mesoscale eddies, but their role in small-scale mixing is not well understood.

There is insufficient information in the XCTD dataset to definitively determine which of the mechanisms listed above, if any, are responsible for the mixing patterns that we observe. This question and questions surrounding the overall importance of mixing in Southern Ocean dynamics can only be answered by future studies. This will partly require development of theoretical models and numerical techniques to evaluate the types of mixing processes and dynamic pathways to turbulence that may be unique for the Southern Ocean. One of the more intriguing processes is the potential role of energetic eddies in enhancing mixing. Eddies may produce interleaving that leads to double-diffusive convection (e.g., Ferrari and Polzin 2005), and they may also interact nonlinearly with the internal wave field to pump energy to small-scale motions (e.g., Zhai et al. 2005). An improved understanding of Southern Ocean mixing processes would also benefit from a dedicated field program in the region, especially one that includes microstructure measurements. Such measurements would help to verify evidence, presented here and in other studies (Naveira Garabato et al. 2004; Sloyan 2005), that small-scale mixing is intense and widespread throughout the water column and likely influences both local Southern Ocean circulation and the global thermohaline circulation.

Acknowledgments. XBT and XCTD sampling in Drake Passage is performed with the assistance of NSFsupported Raytheon Polar Services personnel and other cruise participants. Their support is appreciated and essential to the continued success of the sampling program. We thank Alberto Naveira Garabato both for conversations that led us to pursue this study and for sharing data from Drake Passage. We have also benefited from discussions with Jody Klymak, Eric Kunze, and Kurt Polzin and from two anonymous reviews. We gratefully acknowledge the following awards that have supported this research: an NDSEG Fellowship (A. F. Thompson), NSF OCE-0049066 (S. T. Gille), and NSF OPP-0337998 (J. Sprintall).

\section{REFERENCES}

Alford, M. H., 2001: Internal swell generation: The spatial distribution of energy flux from the wind to mixed layer nearinertial motions. J. Phys. Oceanogr., 31, 2359-2368.

_ , 2003: Improved global maps and 54-year history of windwork on ocean inertial motions. Geophys. Res. Lett., 30, 1424, doi:10.1029/2002GL016614.

—, and R. Pinkel, 2000: Observations of overturning in the thermocline: The context of ocean mixing. J. Phys. Oceanogr., 30, 805-832.

Bryden, H. L., and S. A. Cunningham, 2003: How wind-forcing and air-sea heat exchange determine the meridional temperature gradient and stratification for the Antarctic Circumpolar Current. J. Geophys. Res., 108, 3275, doi:10.1029/ 2001JC001296.

Caldwell, D. R., and J. N. Moum, 1995: Turbulence and mixing in the ocean. Rev. Geophys., 81 (Suppl.), 1385-1394.

Cessi, P., and M. Fantini, 2004: The eddy-driven thermocline. $J$. Phys. Oceanogr., 34, 2642-2658.

Crawford, W. R., 1986: A comparison of length scales and decay times of turbulence in stably stratified flows. J. Phys. Oceanogr., 16, 1847-1854.

Cunningham, S. A., S. G. Alderson, B. A. King, and M. A. Brandon, 2003: Transport and variability of the Antarctic Circumpolar Current in Drake Passage. J. Geophys. Res., 108, 8084, doi:10.1029/2001JC001147.

Dillon, T. M., 1982: Vertical overturns: A comparison of Thorpe and Ozmidov scales. J. Geophys. Res., 87, 9601-9613.

Efron, B., and G. Gong, 1983: A leisurely look at the bootstrap, the jackknife, and cross-validation. Amer. Stat., 37, 36-48.

Ferrari, R., and K. L. Polzin, 2005: Finescale structure of the $T-S$ relation in the eastern North Atlantic. J. Phys. Oceanogr., 35, 1437-1454.

Ferron, B., H. Mercier, K. Speer, A. Gargett, and K. Polzin, 1998: Mixing in the Romanche Fracture Zone. J. Phys. Oceanogr., 28, 1929-1945.

Finnegan, T. D., D. S. Luther, and R. Lukas, 2002: Observations of enhanced diapycnal mixing near the Hawaiian Ridge. $J$. Phys. Oceanogr., 32, 2988-3002. 
Fofonoff, P., and R. C. Millard Jr., 1983: Algorithms for computation of fundamental properties of seawater. UNESCO Tech. Papers in Marine Science 44, 53 pp.

Galbraith, P. S., and D. E. Kelley, 1996: Identifying overturns in CTD profiles. J. Atmos. Oceanic Technol., 13, 688-702.

Garrett, C., 1982: On the parameterization of diapycnal fluxes due to double-diffusive intrusions. J. Phys. Oceanogr., 12, 952959.

- and W. Munk, 1975: Space-time scales of internal wavesProgress report. J. Geophys. Res., 80, 291-297.

Gille, S. T., 2005: Statistical characterization of zonal and meridional ocean wind stress. J. Atmos. Oceanic Technol., 22, 13531372.

Gregg, M. C., 1977: Variations in intensity of small-scale mixing in the main thermocline. J. Phys. Oceanogr., 7, 436-454.

- 1987: Diapycnal mixing in the thermocline: A review. J. Geophys. Res., 92, 5249-5286.

- 1989: Scaling turbulent dissipation in the thermocline. $J$. Geophys. Res., 94, 9686-9698.

— , and E. Kunze, 1991: Internal wave shear and strain in Santa Monica basin. J. Geophys. Res., 96, 16 709-16 719.

— , T. B. Sanford, and D. P. Winkel, 2003: Reduced mixing from the breaking of internal waves in equatorial ocean waters. Nature, 422, 513-515.

Henyey, F.S., 1991: Scaling of internal wave predictions for $\varepsilon$. Dynamics of Internal Gravity Waves in the Ocean: Proc. 'Aha Huliko'a Hawaiian Winter Workshop, Honolulu, HI, University of Hawaii at Manoa, 233-236.

—_, J. Wright, and S. M. Flatté, 1986: Energy and action flow through the internal wave field: An eikonal approach. J. Geophys. Res., 91, 8487-8495.

Howard, S. L., J. Hyatt, and L. Padman, 2004: Mixing in the pycnocline over the western Antarctic Peninsula shelf during Southern Ocean GLOBEC. Deep-Sea Res. II, 51, 1965-1979.

Johnson, G. C., and H. L. Bryden, 1989: On the size of the Antarctic Circumpolar Current. Deep-Sea Res., 36A, 39-53.

Johnson, H. L., and C. Garrett, 2004: Effects of noise on Thorpe scales and run lengths. J. Phys. Oceanogr., 34, 2359-2372.

Joyce, T. M., W. Zenk, and J. M. Toole, 1978: The anatomy of the Antarctic Polar Front in Drake Passage. J. Geophys. Res., 83, 6093-6114.

Karsten, R., H. Jones, and J. Marshall, 2002: The role of eddy transfer in setting the stratification and transport of a circumpolar current. J. Phys. Oceanogr., 32, 39-54.

Kunze, E., 2003: Yes, we have no abyssal mixing. Near-Boundary Processes and Their Parameterizations: Proc. 'Aha Huliko'a Hawaiian Winter Workshop, Honolulu, HI, University of Hawaii at Manoa, 85-93.

— , and T. B. Sanford, 1996: Abyssal mixing: Where it is not. $J$. Phys. Oceanogr., 26, 2286-2296.

Larson, N. G., and M. C. Gregg, 1983: Turbulent dissipation and shear in thermohaline intrusions. Nature, 306, 26-32.

Martin, J. P., and D. L. Rudnick, 2007: Inferences and observations of turbulent dissipation and mixing in the upper ocean at the Hawaiian Ridge. J. Phys. Oceanogr., 37, 476-494.

McComas, C. H., and P. Müller, 1981: The dynamic balance of internal waves. J. Phys. Oceanogr., 11, 970-986.

Muench, R. D., H. J. S. Fernando, and G. R. Stegen, 1990: Tem- perature and salinity staircases in the northwestern Weddel Sea. J. Phys. Oceanogr., 20, 295-306.

Munk, W. H., 1966: Abyssal recipes. Deep-Sea Res., 13, 207-230.

Nagasawa, M., Y. Niwa, and T. Hibiya, 2000: Spatial and temporal distribution of the wind-induced internal wave energy available for deep water mixing in the North Pacific. J. Geophys. Res., 105, 13 933-13 943.

Naveira Garabato, A. C., K. L. Polzin, B. A. King, K. J. Heywood, and M. Visbeck, 2004: Widespread intense turbulent mixing in the Southern Ocean. Science, 303, 210-213.

Orsi, A. H., T. Whitworth, and W. D. Nowlin, 1995: On the meridional extent and fronts of the Antarctic Circumpolar Current. Deep-Sea Res. I, 42, 641-673.

Osborn, T. R., 1980: Estimates of the local rate of vertical diffusion from dissipation measurements. J. Phys. Oceanogr., 10, 83-89.

Ozmidov, R. V., 1965: On the turbulent exchange in a stably stratified ocean. Izv. Acad. Sci. USSR, Atmos. Oceanic Phys., 1, 861-871.

Peters, H., M. C. Gregg, and T. B. Sanford, 1995: On the parameterization of equatorial turbulence: Effect of finescale variations below the range of the diurnal cycle. J. Geophys. Res., 100, 18 333-18 348.

Polzin, K. L., and E. Firing, 1997: Estimates of diapycnal mixing using LADCP and CTD data from I8S. International WOCE Newsletter, No. 29, WOCE International Project Office, Southampton, United Kingdom, 39-42.

_ J. M. Toole, J. R. Ledwell, and R. W. Schmitt, 1997: Spatial variability of turbulent mixing in the abyssal ocean. Science, 276, 93-96.

Rintoul, S., C. Hughes, and D. Olbers, 2001: The Antarctic Circumpolar Current system. Ocean Circulation and Climate, G. Siedler et al., Eds., International Geophysics Series, Vol. 77, Academic Press, 271-302.

Ruddick, B. R., and J. S. Turner, 1979: The vertical length scale of double-diffusive intrusions. Deep-Sea Res., 26A, 903-913.

Sloyan, B. M., 2005: Spatial variability of mixing in the Southern Ocean. Geophys. Res. Lett., 32, L18603, doi:10.1029/ 2005 GL023568.

Smith, W. F., and D. T. Sandwell, 1997: Global sea floor topography from satellite altimetry and ship depth soundings. Science, 277, 1956-1962.

Speer, K., S. R. Rintoul, and B. Sloyan, 2000: The diabatic Deacon cell. J. Phys. Oceanogr., 30, 3212-3222.

Sprintall, J., 2003: Seasonal to interannual upper-ocean variability in the Drake Passage. J. Mar. Res., 61, 27-57.

Stansfield, K., C. Garrett, and R. Dewey, 2001: The probability distribution of the Thorpe displacement within overturns in Juan de Fuca Strait. J. Phys. Oceanogr., 31, 3421-3434.

Thompson, A. F., and G. Veronis, 2005: Diffusively-driven overturning of a stable density gradient. J. Mar. Res., 63, 291-313.

Thorpe, S. A., 1977: Turbulence and mixing in a Scottish loch. Philos. Trans. Roy. Soc. London, 286A, 125-181.

Timmermans, M. L., C. Garrett, and E. Carmack, 2003: The thermohaline structure and evolution of the deep waters in the Canada Basin, Arctic Ocean. Deep-Sea Res. I, 50, 1305-1321.

Toggweiler, J. R., and B. Samuels, 1995: Effect of Drake Passage on the global thermohaline circulation. Deep-Sea Res. I, 42, 477-500.

Toole, J. M., 1981: Intrusion characteristics in the Antarctic Polar Front. J. Phys. Oceanogr., 11, 780-793.

_, K. L. Polzin, and R. W. Schmitt, 1994: Estimates of diapycnal mixing in the abyssal ocean. Science, 264, 1120-1123. 
Walsh, D., and B. Ruddick, 2000: Double-diffusive interleaving in the presence of turbulence: The effect of a nonconstant flux ration. J. Phys. Oceanogr., 30, 2231-2245.

Wijesekera, H., L. Padman, T. Dillon, M. Levine, C. Paulson, and R. Pinkel, 1993: The application of internal-wave dissipation models to a region of strong mixing. J. Phys. Oceanogr., 23, 269-286.

Winkel, D. P., 1998: Influences of mean shear in the Florida Cur- rent on turbulent production by internal waves. Ph.D. dissertation, University of Washington, 137 pp.

Wunsch, C., 1998: The work done by the wind on the oceanic general circulation. J. Phys. Oceanogr., 28, 2332-2340.

Zhai, X., R. J. Greatbatch, and J. Zhao, 2005: Enhanced vertical propagation of storm-induced near-inertial energy in an eddying ocean channel model. Geophys. Res. Lett., 32, L18602, doi:10.1029/2005GL023643. 